\title{
III. Über die Frontkämpfer zur Dienststelle Ribbentrop
}

\author{
1. Anstoß für eine diplomatische Karriere: \\ Abetz' Kontaktaufnahme mit den Anciens combattants
}

Kaum in Diensten Schirachs, unternahm Abetz den spektakulären Versuch, ein Millionenpublikum in Deutschland und Frankreich einander näherzubringen: die Veteranen des Ersten Weltkriegs. Den Anstoß gab ein Auftritt des ,Führer'-Stellvertreters Rudolf Heß am 8. Juli 1934 auf dem Ostpreußischen Gauparteitag in Königsberg. Nach einer Schilderung von Hitlers angeblich heroischem Durchgreifen im Fall Röhm, wozu nur ein „soldatischer Mensch“ seines Kalibers fähig sei, propagierte $\mathrm{He} ß$, ans Ausland gerichtet, den Friedenswillen der nationalsozialistischen Führung. Er bezeichnete es als großes Glück, daß Deutschland jetzt vorwiegend von ehemaligen Frontkämpfern gelenkt werde, welche die Tugenden der Front auf die Staatsgeschäfte übertrügen. Ihr wichtigstes Anliegen sei die Erhaltung des Friedens, ein Wunsch, der alle Weltkriegsteilnehmer, von denselben leidvollen Erfahrungen geprägt, beseele. Gerade sie, die „den Tod furchtbarer und geballter gesehen als wohl je Menschen vor uns“, seien berufen, „die Brücke des Verstehens [...] von Volk zu Volk zu schlagen“, bevor „wieder eine unfähige Diplomatie uns in eine Katastrophe hineinstolpern läßt". Ein solches Verhängnis gelte es in gemeinsamer Anstrengung abzuwenden, und $\mathrm{Heß}$ appellierte an „die Frontkämpfer in anderen Staaten, ebenso wie an die Gutwilligen in den Regierungen dieser Staaten, uns in diesem Ziel zu unterstützen“. Freudig habe man Verlautbarungen französischer Veteranenverbände vernommen, die von aufrichtiger Verständigungsbereitschaft zeugten, ein Verlangen, das der Kenntnis vom wahren Gesicht des Krieges entspringe, aber auch jener Hochachtung, welche die einstigen Gegner einander zollten. Abrupt die Tonlage wechselnd, forderte Heß sodann "Gleichberechtigung auf allen Gebieten einschließlich denen der Rüstung" und warnte davor, das nach friedlicher Koexistenz in Europa strebende Reich mit „dem Deutschland von einst, dem Deutschland des Pazifismus“ zu verwechseln. Bei allem Abscheu vor dem Krieg - gegen einen militärischen Angreifer würden seine Landsleute jede Handbreit Boden mit letzter Kraft verteidigen ${ }^{1}$.

Heß' Worte, auch über Rundfunk verbreitet, fanden in Frankreich einige Beachtung. Die Pariser Mittagspresse stehe „völlig im Zeichen der großangelegten Rede“, meldete tags darauf das Deutsche Nachrichtenbüro" ${ }^{2}$ Das Echo war allerdings fast durchweg ungünstig, wie Botschafter Köster telegraphierte. Zahlreiche Kommentatoren tadelten die „Verquickung von Drohungen mit Schmeicheleien“,

1 „Die große Friedensrede des Stellvertreters des Führers. Rudolf Heß in Königsberg “; Völkischer Beobachter, 10. 7. 1934. In Auszügen abgedruckt Schulthess' 1934, S. 170 f.

2 DNB-Rohmaterial, 9. 7. 1934; PA/A'A, R 70556. 
ziehen die Deutschen mangelnder Aufrichtigkeit und unterstellten ihnen einen „Absprengungsversuch“ der Kriegsteilnehmer von der Regierung, mithin eine unzulässige Einmischung in die französische Innenpolitik. Die kritischen Reaktionen vor Augen, empfahl Köster, Frontkämpferkontakte müßten „sehr vorsichtig angepackt werden und vorläufig auf individuelle Fühlungnahmen beschränkt bleiben, wenn man sichere Fundamente schaffen will“". Besonders bei den mitgliederstarken linksgerichteten Veteranenverbänden gebe es massive Gegner der amtierenden Reichsregierung ${ }^{3}$.

Die von Köster diskutierte Fühlungnahme erfolgte postwendend, freilich nicht in Regie des Auswärtigen Amtes, sondern durch den unkonventionell und unbekümmert vorgehenden diplomatischen Außenseiter Abetz. Er hielt sich seit Ende Juni in Paris auf, als Gast eines von Jean Luchaire organisierten Jugendkongresses und um im Auftrag der HJ Lager- und Fahrttermine zu vereinbaren ${ }^{4}$. Heß' Worte elektrisierten ihn. Er sah eine einmalige Chance, sein Ideal, die deutsch-französische Aussöhnung, auf breiter Ebene voranzutreiben: Höchste Kreise in Berlin ermunterten öffentlich dazu. Unverzüglich suchte er französische Frontkämpferfunktionäre auf und drängte sie, mit ihren deutschen, in der Nationalsozialistischen Kriegsopferversorgung (NSKOV) zusammengeschlossenen Kameraden in Verbindung zu treten. Zwei Organisationen beherrschten das Feld, die „Union fédérale des associations françaises d'anciens combattants et de victimes de la guerre" (UF) mit über 900000 Mitgliedern und die politisch weiter rechts angesiedelte, etwa 860000 Anhänger zählende "Union nationale de combattants“ (UNC). Daneben gab es „La Semaine du combattant", einen losen Zusammenschluß regionaler Veteranengruppen (250000 Mitglieder), die militärisch straff geführten faschistischen "Croix de feu“ (nach eigenen Angaben etwa 300000) sowie zahlreiche kleinere Versehrtenverbände ${ }^{5}$. Nahezu allen gemein war der ausgeprägte Wunsch, ein zweites Blutbad wie in den Jahren 1914 bis 1918, als 1,4 Millionen französische Soldaten ihr Leben ließen, zu vermeiden. Entsprechend defensiv war die Grundhaltung der Überlebenden und groß ihre Bereitschaft, mit Schicksalsgenossen auch aus den ehemaligen Feindnationen ins Gespräch zu kommen.

Einen nachgerade idealen Ansprechpartner fand Abetz in Henri Pichot, dem Vorsitzenden der Union fédérale ${ }^{6}$. Der Volksschullehrer aus Orléans, im August

3 Köster an Auswärtiges Amt, 11. 7. 1934, ebenda.

4 Berichte der Sûreté Nationale vom 7.12. 1934 („Au sujet de Jean Luchaire et des Allemands“) und vom 2.7.1935 („Au sujet de Otto Abetz, envoyé spécial de Ribbentrop“); AN, F 7/13433.

5 Vgl. Antoine Prost, Les anciens combattants français et l'Allemagne (1933-1938), in: La France et l'Allemagne 1932-1936, S. 132f. Distelbarth, Lebendiges Frankreich, S. 185 ff. Über die militant gegen die Parteien der Linken agierenden, 1936 verbotenen Croix de feu und ihren politischen Arm, Parti social populaire, siehe auch Klaus-Jürgen Müller, Betrachtungen zum Deutschlandbild der französischen extremen Rechten, in: Büttner (Hrsg.), Unrechtsregime, I, S. 474, $479 \mathrm{ff}$.

6 Geb. 27.6. 1884 in Decize/Nièvre, gest. 13.1. 1945 in Orléans. Biographische Angaben nach: handschriftl. Datenblatt im Nachl. Pichot, AN, 43 AS 1, dr. 4; „Bilan 1916-1940“, handschriftl. Manuskript und masch. Abschrift (17 S.), unterzeichnet „15 décembre $1944^{“,}, 43$ AS 4, dr. 3. 
1914 als Infanterist ausgezogen, war schon nach wenigen Kriegstagen schwerverwundet in deutsche Gefangenschaft geraten. Im Juli 1915 entlassen und heimgekehrt, wurde er Frontkämpferfunktionär der ersten Stunde. Im Dezember 1916 gründete er die „Association des mutilés du Loiret“, deren Vorsitz er bis 1940 innehatte. „J'ai fait d'Orléans une grande capitale provinciale de l'Esprit Combattant“, zog er zufrieden Bilanz. Rasch stieg er in die Führungsriege der 1918 entstandenen UF auf, wurde mehrfach zum Präsidenten gewählt - von Mai 1934 bis Juni 1940 bekleidete er das Amt ununterbrochen - und entfaltete eine rege publizistische Tätigkeit. Der charakterfeste, aufrechte Republikaner, 1922 in Würdigung seines rastlosen Einsatzes für die Kriegsopfer zum Ritter der Ehrenlegion ernannt, genoß enormes Prestige unter seinesgleichen. Freunde rühmten sein Organisationstalent, Gegner fürchteten die spitze Feder. Wiederholte Versuche von Staatsmännern, ihn für eine bei seiner Popularität gewiß aussichtsreiche Parlamentskandidatur zu gewinnen, blieben erfolglos. Pichot wollte seine Kameraden nicht im Stich lassen und hielt im Gegensatz zu anderen prominenten Frontkämpferführern wie Jean Goy Verbandsposten und politisches Mandat für unvereinbar7. Nie begnügte er sich damit, für höhere Pensionen zu streiten - stets interessierten ihn die großen Zusammenhänge. Nach den Unruhen des 6. Februar 1934 rief er ein "Centre d'études de l'Union fédérale“ ins Leben, ein Studienkomitee, das wirtschaftliche und soziale Probleme analysierte und im November mit einem Plan zur nationalen Erneuerung Frankreichs an die Öffentlichkeit trat. Auch einen Dachverband für 3,5 Millionen französische Veteranen und internationale Kontakte mit ehemaligen Verbündeten wie Gegnern hat er maßgeblich gefördert. Via Genf unterhielt die UF, die Briand und den Völkerbund offen unterstützte, unter anderem Beziehungen zum SPD-nahen Reichsbund der Kriegsbeschädigten. Die beiden Organisationen bildeten das Rückgrat der 1926 gegründeten, zeitweilig bis zu 4,5 Millionen Menschen repräsentierenden „Conférence internationale des associations de mutilés et anciens combattants" (CIAMAC), die Pichot von 1930 bis 1932 leitete und an der sich auch Italiener, Österreicher, Dänen, Polen, Tschechen, Rumänen, Bulgaren und Jugoslawen beteiligten. Im Urteil des deutschen Kriegsveteranen und Frankreichkenners Paul Distelbarth war sie die gelungene Vorwegnahme einer künftigen europäischen Völkergemeinschaft, „beseelt" von Brüderlichkeit und gegenseitiger Achtung. Die CIAMAC erregte Aufsehen, als sie sich 1932 auf Einigung drängend in die Lausanner Reparationskonferenz einschaltete und besonders den deutschen und französischen Unterhändlern nahelegte, dem Beispiel der Frontkämpfer folgend vertrauensvolle Beziehungen herzustellen. 1933 wurden die Drähte nach Deutschland jäh gekappt, als sich Reichsbund und Reichsbanner auf Geheiß der Regierung Hitler aus der CIAMAC zurückzogen und erzwungenermaßen in der gleichgeschalteten NSKOV aufgingen. Nichts habe das Mißtrauen der Anciens combattants mehr geschürt als

7 Am 16. 2. 1935 schrieb er in diesem Sinn an Camille Chautemps: „Soit dit en tout modestie, mon départ de l'Union fédérale causerait indubitablement à l'U.F., et peut-être à l'ensemble du mouvement combattant, un tort marqué. Il est à peu près impossible de détenir un mandat politique [...] et de diriger en même temps une action civique combattante qui revêt un caractère en quelque sorte extra-politique." $\mathrm{AN}, 43 \mathrm{AS}$ 1, dr. 2. 
dieser Austritt, vermerkte Distelbarth. Daß aber eine neue Regierung die anerkannt friedliebende Gesinnung der deutschen Kameraden verbiegen könnte, erschien ihnen ausgeschlossen, eine Verständigung mithin unverändert möglich. Und wiewohl Pichot als entschiedener Antifaschist galt, hielt er es - ähnlich wie Jean Luchaire - für wünschenswert und der nationalen Sicherheit dienlich, auch über tiefe ideologische Gräben hinweg das Gespräch und den Ausgleich zu suchen ${ }^{8}$.

Einige Tage nach der Königsberger Rede von Rudolf Heß saß Abetz in Pichots Pariser Büro: „un jeune homme, partant la trentaine, grand, blond, la figure ouverte, le regard droit, l'allure dégagée [...], parlant un français courant, aisé, correct et sans accent étranger." 9 Nach Informationen der Sûreté hatte Jean Luchaire das Treffen eingefädelt ${ }^{10}$. Pichots Erinnerungen zufolge vermittelte sein Besucher den Eindruck, im Namen von Hitlerjugend und NSKOV zu sprechen, die beide in Sachen Völkerverständigung engagiert seien. Abetz unterbreitete den Vorschlag, zum 20. Jahrestag des Kriegsausbruchs Anfang August nachts an beiden Rheinufern große Feuer anzuzünden: „Ces flammes seront le symbole de la possible reconciliation." 11 Pichot fand die Idee originell, jedoch die verbleibende Zeit zur Vorbereitung zu knapp. Er erklärte sich aber einverstanden, inoffiziell, als Privatmann, an einem grenznahen Ort mit deutschen Frontkämpfern zusammenzukommen. Das Treffen wurde schon am 2. August 1934 in einem Hotel in Baden-

8 Zur Geschichte der CIAMAC Distelbarth, Lebendiges Frankreich, S. 202 ff.; Prost, Les anciens combattants et la société française 1934-1939, 1, S. 104 ff.; Fagerberg, The „Anciens Combattants“, S. $55 \mathrm{ff}$.

9 Pichot, Et ce fut quand même la guerre, pag. 14f., auch zum Folgenden; AN, 43 AS 5.

10 „Oui, je suis à la base de l'affaire“, soll er Berufskollegen bestätigt haben. Bericht der Sûreté Nationale vom 24. 11. 1934; AN, F 7/13433. Auch in nachrichtendienstlichen Aufzeichnungen vom 7. und 8. Dezember werden Luchaire und Abetz als Urheber der jüngsten Frontkämpferkontakte genannt; ebenda. Die Pariser Zeitung L'Europe Nouvelle dagegen präsentierte Bertrand de Jouvenel als entscheidenden Mittelsmann, der Abetz dank seiner Beziehungen wichtige Türen bei den Anciens combattants öffnete; „Histoire secrète du rapprochement franco-allemand“, in: L'Europe Nouvelle, 15. 12. 1934.

11 Laut Jouvenel regte Abetz an, zwei dem, unbekannten Soldaten' geweihte, mit den Landesflaggen geschmückte Särge auf einem Floß rheinabwärts treiben zu lassen, vorbei an salutierenden Frontkämpfern an beiden Ufern; Jouvenel, Voyageur, S. 202. Eine nicht minder spektakuläre Geste soll Hitler selbst im Herbst 1933 erwogen haben. Er wollte angeblich den französischen Ministerpräsidenten Daladier auf der Kehler Rheinbrücke treffen, einen den Kriegstoten beider Nationen geweihten Kranz in die Fluten werfen und Frankreich einen „Frieden der Frontkämpfer" offerieren.Vgl. Kupferman, Diplomatie parallèle, S. 86. Der Journalist Pertinax (i.e. André Géraud) behauptete, rechtslastige Blätter hätten entsprechende Gerüchte gestreut, um das Kabinett Daladier zu diskreditieren; Les Fossoyeurs, 2, S. 144 f. Daladier wiederum berichtete von einer abenteuerlich klingenden Offerte Ribbentrops, ihn mit der ,Führer'-Maschine zu einer geheimen Unterredung mit Hitler nach Deutschland zu fliegen (Les procès de collaboration, S. 203f.), eine Variante, deren Verwirklichung laut Abetz im letzten Moment am zaudernden Pariser Premier scheiterte. Das Flugzeug, das Daladier zum vereinbarten Treffpunkt, einer Jagdhütte im Taunus, bringen sollte, sei unverrichteter Dinge zurückgekehrt (Das offene Problem, S. 116). Vorschläge und Projekte dieser Art hatten damals offenbar Konjunktur; die meisten fallen in eine Periode geschäftiger Paralleldiplomatie, die Ribbentrop im zweiten Halbjahr 1933 entfaltete. 
Baden arrangiert, wo drei hochrangige NSKOV-Funktionäre den Franzosen begrüßten: Reichskriegsopferführer Hanns Oberlindober, sein Adjutant Max v. Cossel und Pressechef Alfred Dick, den Pichot von einem 1912 in Kaiserslautern absolvierten Sprachkurs her kannte. Abetz fungierte als Dolmetscher. Erörtert wurden materielle Sorgen der Veteranen, die Organisationsstrukturen ihrer Verbände und Möglichkeiten, einander regelmäßig auszutauschen und beruhigend auf die öffentliche Meinung in beiden Ländern einzuwirken. Besonderes Augenmerk sollte hierbei der Presse gelten. Als weiteres Ziel wurde die Erziehung der Jugend in versöhnlichem Geist genannt ${ }^{12}$. Nach dreistündiger ${ }_{n}$ freier und zwangloser Aussprache" schien das Eis gebrochen. Pichot schwärmte später von einem verheißungsvollen "Lichtblick“ für die Zukunft der bilateralen Frontkämpferbeziehungen, denen mit dem Aufstieg der Nationalsozialisten eine lange Zwangspause gedroht hatte ${ }^{13}$. Seine Gastgeber drängten ihn, unverzüglich Hitler aufzusuchen und sich von der Verständigungsbereitschaft des Kanzlers persönlich zu überzeugen. Mit der Begründung, hierzu von seinem Verband nicht autorisiert zu sein, winkte Pichot jedoch erst einmal ab. Sein verhaltener Optimismus verleitete ihn nicht zu überstürzten Handlungen.

$\mathrm{Ob}$ Abetz seine ersten Verbindungen zu Frankreichs Veteranen tatsächlich ohne höheren Auftrag knüpfte, wie spätere Aussagen glauben machen ${ }^{14}$, ist anhand der spärlich vorhandenen Quellen nicht zu belegen. Das auffallend schnell zustande gekommene Treffen in Baden-Baden, nach seiner Initiative nur eine Sache von Tagen, läßt Spekulationen Raum, daß er nicht gänzlich auf eigene Faust handelte ${ }^{15}$. Daß er am 2. August 1934 bereits im Namen Ribbentrops und mit entsprechenden Kompetenzen versehen auftrat, wie in seinen Memoiren anklingt ${ }^{16}$, würde Oberlindobers rasche Mobilisierung erklären helfen. Wie spontan Abetz' Vorstoß gewesen sein mag, er erscheint als ein klug berechneter, der eigenen Absicherung dienlicher Schritt: Männer, die ihren Patriotismus auf den Schlachtfeldern bewiesen hatten, waren prädestiniert, seine in Parteikreisen aus Mißgunst und ideologischen Vorbehalten von manchen argwöhnisch beäugte Arbeit gegen den Vorwurf des unvaterländischen Pazifismus zu verwahren. In der $\mathrm{HJ}$ habe er viele Leute für die Verständigungsidee gewonnen, sei dabei allerdings auch ins Kreuzfeuer der Kritik geraten, erzählte er bei einer Vernehmung im Mai 1947. Die Klagen seien bis zur Reichswehr durchgedrungen. „Um uns zu decken, haben wir dann Fühlung mit den Frontkämpfern genommen [...], damit der Patriotismus in der Organisation nicht mehr in Zweifel gestellt werden konnte. "17 Gemeinsam, verkündete eine neueröffnete Rubrik „Die Stimme der Frontgeneration“ in den

12 Abetz, Die Stimme der Frontgeneration, in: DFM, Dezember 1934, S. 70; ders., Das offene Problem, S. 52.

13 "Allocution devant la D.F.G. et les anciens combattants“, Bremen und Lübeck, 25./26.11. 1937, Manuskript (11 S.) und deutsche Übersetzung; AN, 43 AS 2, dr. 1.

14 Vgl. Abetz, Das offene Problem, S. 41.

15 Diese Vermutung bei Jouvenel, Voyageur, S. 202.

16 Abetz, S. 52. Mühle, Frankreich und Hitler, S. 327, geht hiervon aus.

17 Vernehmung durch John Fried, 28. 5. 1947; StA Nürnberg, KV-Anklage, Interrogations, A 2. 
Deutsch-Französischen Monatsheften, werde man eine unwiderstehliche Allianz („une alliance irrésistible") bilden ${ }^{18}$.

Umfang und Bedeutung der Konferenz vom 2. August gab Abetz in seinen Erinnerungen offenkundig falsch wieder ${ }^{19}$. Er schrieb, in Baden-Baden seien die Repräsentanten von 3,5 Millionen französischen Frontkämpfern zugange gewesen, was bedeuten würde, daß Henri Pichot nicht allein kam. Von Delegierten anderer Veteranenverbände ist jedoch nirgends die Rede, ebensowenig davon, daß bereits damals regelmäßige Besuche und Tagungen vereinbart wurden. Das hätte einen offiziellen Gesprächscharakter vorausgesetzt; doch Abetz selbst vermerkte lediglich, daß Pichot auf Einladung deutscher Kriegsteilnehmer als Privatmann angereist $\operatorname{sei}^{20}$.

Wenig später allerdings sollten die Kontakte wie auch Abetz' Karriere einen ungeahnten Aufschwung nehmen, obgleich es zunächst so aussah, als hätte er sich mit seinem Vorstoß bei Pichot zuhause tüchtig in die Nesseln gesetzt ${ }^{21}$. Aus Paris zurückgekehrt, schickte er der Reichsjugendführung einen Bericht über seine Aktivitäten, im besonderen über seine Erfahrungen mit den französischen Frontkämpfern. Schirach leitete das Schriftstück an Heß weiter, in dessen Stab Joachim v. Ribbentrop gastierte, „Sonderbeauftragter für Abrüstungsfragen“ und HitlerIntimus in außenpolitischen Dingen. Ribbentrop bestellte den ihm bis dahin gänzlich unbekannten Abetz ein, offenbar in der Absicht, ihm wegen eigenmächtiger Auslandsarbeit die Leviten zu lesen. „Da bildet sich wohl jede Gliederung der Partei ein, nach Gutdünken im Ausland herummurksen zu können. Der Führer hat mich eingesetzt, da gründlich Remedur zu schaffen." Er schien den Bericht jedoch nur überflogen zu haben und horchte auf, als ihm sein Gegenüber darlegte, Millionen französischer Veteranen stünden bereit, mit ihren deutschen Kameraden in Fühlung zu treten. Plötzlich wie umgewandelt, ernannte er den verdutzten Abetz „auf der Stelle“ zum Frankreichreferenten seines Büros. Er hat anscheinend sogleich erkannt, daß dieser HJ-Führer für ihn und seine Ziele ein wichtiger Mittelsmann werden konnte.

\section{Verständigung aus machtpolitischem Antrieb: "Sonderbotschafter" Joachim v. Ribbentrop}

Schenkt man Ribbentrops Memoiren Glauben, dann erläuterte ihm Hitler im Februar 1933, unmittelbar nachdem er Reichskanzler geworden war, seine außenpolitischen Ziele. Antikommunismus und Revisionismus bildeten eine gemeinsame weltanschauliche Basis, in der Bewertung Frankreichs traten Unterschiede zutage. Während sich der ,Führer', getreu seinen programmatischen Axiomen, sehr negativ äußerte, will Ribbentrop von Anfang an eine Normalisierung des deutsch-

18 Abetz, Die Stimme der Frontgeneration, wie Anm. 12.

19 Wie Anm. 16.

20 Wie Anm. 18.

21 Wir sind im folgenden, in Ermangelung anderer Quellen, auf Abetz' Memoiren angewiesen; Das offene Problem, S. $42 \mathrm{f}$. 
französischen Verhältnisses befürwortet haben ${ }^{22}$. Biographische Hintergründe mochten hierbei eine Rolle spielen. Der Offizierssohn ging in Metz zur Schule, lebte einige Zeit in der französischsprachigen Schweiz, in Grenoble und Kanada, ehe er in den zwanziger Jahren als Wein- und Spirituosenhändler enge Geschäftsbeziehungen nach Frankreich unterhielt, an die er als Politiker zum Teil anknüpfen konnte. Entscheidend war aber wohl, daß er einen Ausgleich mit dem westlichen Nachbarland als unumgänglich für eine erfolgversprechende deutsche Revisionspolitik erachtete. Auch glaubte er, daß nur über ein solches Agreement das von Hitler sehnlich erhoffte Bündnis mit England zu realisieren sei. Mit dieser Konzeption bewegte er sich in den konservativen Gedankenbahnen eines Franz v. Papen, dem ein kontinentaleuropäischer Block Deutschland-Frankreich-Italien-Polen vorschwebte, der letztlich die Klein- und Mittelstaaten absorbieren und ein ideologisches Bollwerk gegen den Bolschewismus errichten würde ${ }^{23}$.

Ribbentrop sah seine Bemühungen, Hitler vom machtpolitischen Nutzen einer deutsch-französischen Kooperation zu überzeugen, von Erfolg gekrönt: „Ich merkte, daß er zusehends Interesse für französische Dinge zeigte [...] Er hat mir dann gesagt, daß ich auf dem von mir [...] verfolgten Wege der Verständigung zwischen Deutschland und Frankreich fortfahren und ihm weiter über diese Dinge berichten sollte. " 24 Hitlers Auftrag verwundert kaum, denn er wußte, wie wichtig während der risikoreichen Phase der ,Wehrhaftmachung' ein französisches Stillhalten war. Taktische Erfordernisse ließen ihn Initiativen gutheißen, die das deutsch-französische Verhältnis entkrampften und das Reich gegen unerwünschte Einwirkungen von außen abschirmten. Das Streben, sich dem multilateralen Völkerbund-System zu entziehen, ging dabei Hand in Hand mit seiner Vorliebe für persönliche Kontakte abseits der protokollarisch vorgeschriebenen Pfade. Den Berichten des Auswärtigen Amts mißtraute er notorisch, den dort tätigen Beamten attestierte er veraltete Methoden und mangelnde nationalsozialistische Gesinnung ${ }^{25}$. Solchermaßen begünstigt, herrschte Konjunktur in jener diplomatischen Grauzone, in der halboffizielle zwischenstaatliche Fühlungnahmen angebahnt wurden. Immer häufiger geschah dies am Auswärtigen Amt vorbei, und "genau an dieser Stelle" sind auch Ribbentrops Vorstöße in Frankreich in den Jahren 1933 bis 1935 zu verorten ${ }^{26}$. Der ehrgeizige, bedingungslos servile Gefolgsmann Hitlers, rasch in die Rolle des außenpolitischen Sonderberaters hineingewachsen, wollte unbedingt einen Dialog auf höchster Ebene in Gang bringen.

22 v. Ribbentrop, Zwischen London und Moskau, S. $42 \mathrm{ff} ., 51 \mathrm{f}$.

23 Michalka, Ribbentrop, S. 53, 64 f., 123, 298 ff.; Jacobsen, Außenpolitik, S. 255 ff.; quellenkritische Anmerkungen hierzu von Longerich, Propagandisten, S. 42 ff. Die Anfänge von Ribbentrops NS-Karriere und sein Weltbild werden auch in zwei englischen Biographien neueren Datums ausführlich behandelt: Michael Bloch, Ribbentrop; Weitz, Ribbentrop. Hitler's Diplomat. Siehe ferner Charles Bloch, Das Dritte Reich, S. $51 \mathrm{ff}$.

24 Aussage Ribbentrops vom 29. 3. 1946; IMT, X, S. $261 \mathrm{f}$.

25 Einige abfällige Bemerkungen Hitlers über das Auswärtige Amt („Verschwörergesellschaft", „Kamarilla“, „ein wahrer Schuttplatz der Intelligenz") auch bei Jacobsen, Zur Struktur der NS-Außenpolitik, in: Funke (Hrsg.), Hitler, S. 142.

26 Michalka, Ribbentrop, S. 66. 
Wichtigster Verbindungsmann auf französischer Seite war Fernand de Brinon, den Ribbentrop im Herbst 1932 während einer Eisenbahnfahrt von Paris nach Reims kennenlernte. Beide waren, wie sich herausstellte, unterwegs zu einer Jagdpartie der Familie Polignac, mit der Ribbentrop in seiner Eigenschaft als Champagner-Importeur („Pomméry“) verkehrte. Brinon, 1885 als Sohn eines Landadeligen in Libourne/Gironde geboren, hatte nach abgeschlossener Juristenausbildung eine journalistische Laufbahn eingeschlagen. Im Ersten Weltkrieg diente er als Dragoner und Artillerist, später in den Informationsabteilungen des französischen Hauptquartiers und des Kriegsministeriums, 1919 kurzfristig im persönlichen Stab von Ministerpräsident Clémenceau. Aus dieser Zeit besaß er nützliche Kontakte, unter anderem zu André Tardieu, den er auf zahlreiche internationale Konferenzen begleitete. Nach Kriegsende nahm er seinen alten Platz beim Journal des Débats wieder ein, wurde leitender Redakteur und Deutschlandexperte des angesehenen, von François de Wendel finanzierten Blattes. Mit Reportagen über die Reparationsprobleme des Reiches und die gespannte Lage an der Ruhr profilierte er sich zu Beginn der zwanziger Jahre als Gegner der Politik Poincarés und entschiedener Befürworter eines deutsch-französischen Ausgleichs. Dahinter standen nüchterne Überlegungen: Brinon fürchtete, Frankreich könnte sich international ins Abseits manövrieren, und ahnte, beeindruckt von Moral und Disziplin der rechtsrheinischen Nachbarn, daß sich die europäische Gesamtlage irgendwann zu deutschen Gunsten entwickeln würde. Deshalb forderte er, Frankreich solle von unhaltbar gewordenen Positionen abrücken und in allen strittigen Fragen eine Übereinkunft nach dem Prinzip des do ut des mit dem Reich anstreben, was eine solide Friedensgarantie wäre. Anderseits machte auch er geltend, erschütternde Einblicke in die Leiden der Soldaten hätten ihm den Irrsinn des Krieges vor Augen geführt und den Grundstein für sein Wirken um Aussöhnung gelegt. Im Juli 1931 berichtete er aus Berlin über die Bankenkrise und interviewte Brüning, der ihm angeblich vertrauliche Vorschläge an die Adresse Lavals mit auf den Weg gab. 1932 wechselte er als Ressortleiter Außenpolitik zum Wirtschaftsfachblatt L'Information. Auf der Londoner Weltwirtschaftskonferenz im Juli 1933 hielt er im Auftrag Daladiers Verbindung zu den deutschen Unterhändlern. Wenige Wochen später ernannte Daladier, mit Brinon seit längerem bekannt („une amitié qui devient très intime par la suite“), den germanophilen Helfer zum Ritter der Ehrenlegion ${ }^{27}$.

Ribbentrops Vision einer deutsch-französischen Partnerschaft begeisterte Brinon. Gern folgte er einer Einladung nach Berlin, erlebte eine Kundgebung des "Führers' im Sportpalast und wurde einigen lokalen Parteigrößen vorgestellt. Nach der nationalsozialistischen Machtübernahme bemühte er sich gemeinsam

27 Für „services éminents rendus à la cause française à l'étranger“, wie es in der Laudatio hieß. Die Vermutung liegt nahe, daß Brinon auch für die Erschließung des Kontaktes zu Ribbentrop belohnt werden sollte, den Daladier zum damaligen Zeitpunkt nutzte, um über den außenpolitischen Kurs der Regierung Hitler Klarheit zu gewinnen. Die Angaben zur Person Brinons sind zwei autobiographischen Aufzeichnungen aus seinem Nachlaß entnommen; AN, 411 AP 7, dr. 3. Vgl. auch Duroselle, La décadence, S. 206. Über „Fernand de Brinon und Deutschland" neuerdings auch eine Bonner Dissertation von Corinna Franz. 
mit Ribbentrop, direkte Gespräche, vielleicht ein Gipfeltreffen anzubahnen. Zu diesem Zweck verschafften die beiden einander wechselseitig Entrée bei ihren Regierungschefs. Im Sommer 1933 traf der deutsche Emissär den französischen Ministerpräsidenten an ungestörten Orten wie Brinons Apartments in Neuilly und Vichy, angeblich auch noch Anfang November, als Daladier schon Kriegsminister im Kabinett Sarraut und das Reich abrupt aus Völkerbund und Abrüstungskonferenz ausgeschert war ${ }^{28}$. Brinon seinerseits wurde am 8. September in Berlin von General v. Blomberg empfangen und von ihm und Ribbentrop zu Hitler nach Berchtesgaden eskortiert, wo er sich als Abgesandter Daladiers vorstellte. Ende September weilte er erneut zu informellen Gesprächen in der Reichshauptstadt. Der Kanzler und sein Wehrminister verteidigten geschickt den Rückzug aus Genf, indem sie ihre Bereitschaft zu Verhandlungen mit Frankreich beteuerten, zwar vehement die Rückkehr des Saargebiets zu Deutschland forderten, aber gleichzeitig militärischen Abenteuern und einem Anschluß Österreichs abschworen und Interesse an Zollvereinbarungen und einer bilateralen Rüstungskonvention bekundeten ${ }^{29}$.

Wiewohl die Initiativen im Sande verliefen, war Brinon für die Zukunft als verläßlicher, weitgehend unkritischer Interpret der nationalsozialistischen Frankreichpolitik und Sprachrohr für Hitlers Beschwichtigungsmanöver gewonnen, spätestens, nachdem ihm der ,Führer' am 19. November als erstem französischem Korrespondenten ein Interview gewährt hatte, das Aufsehen erregte und seinen journalistischen Marktwert beträchtlich steigerte. Der Inhalt ist exemplarisch für die Hitlersche Rhetorik jener Jahre, wie Interviews überhaupt zu den bevorzugten Methoden des Reichskanzlers gehörten, im Ausland um Vertrauen zu werben. „Es ist eine Beleidigung für mich, wenn man mir immer wieder davon spricht, ich wollte Krieg“, erklärte er Brinon. „Ich wäre ein Narr!“ Er wolle friedlich im Innern wirken, die Not in Deutschland lindern, dem Volk die Lebensfreude wiederschenken und seine Arbeit keinesfalls durch kriegerische Verwicklungen gefährden. Auf frankreichfeindliche Passagen in Mein Kampf angesprochen, winkte er ab: Er habe das Buch mit der Empörung eines verfolgten Apostels geschrieben, die inkriminierten Stellen seien überholt. Ein Politiker berichtige sich indes nicht durch Worte, sondern durch Taten; deshalb trete er jetzt "mit allem Nachdruck“

28 So die Darstellung Brinons, Les procès de collaboration, S. 53 ff., und AN, 411 AP 7, dr. 3. Daladier mochte 1947 im Zeugenstand lediglich bestätigen, Brinon zu Sondierungen über die deutschen Absichten ermuntert und seine Berichte erhalten zu haben; ebenda, S. $203 \mathrm{ff}$. Neuere Forschungsarbeiten bekräftigen dagegen, daß er Brinon als Emissär in Marsch setzte, ein Akt von Paralleldiplomatie an Botschafter François-Poncet vorbei, der zwar dezidiert für bilaterale Verhandlungen eintrat, damit jedoch im Widerspruch zu Außenminister Paul-Boncour stand. Vgl. Vaïsse, Sécurité d'abord, S. 440 ff.; Messemer, FrançoisPoncet und Deutschland, S. 523.

29 Die Unterredungen protokollierte Brinon zum Teil auf Briefbögen mit Ribbentrops Dahlemer Privatanschrift; AN, 411 AP 1, dr. 3. Ausführlich zu diesen Missionen Mühle, Frankreich und Hitler, S. 110-123. Siehe auch du Réau, Daladier, S. $112 \mathrm{ff}$. Im Juli 1935 war Brinon wieder - und nicht zum letzten $\mathrm{Mal}$ - in inoffizieller, vermittelnder Funktion in Deutschland, hatte eine lange Unterredung mit Hitler und Ribbentrop und berichtete Laval; „Rapport“ vom 24. 7. 1935 (20 S.) im Nachl. Brinon. 
für eine deutsch-französische Verständigung ein ${ }^{30}$. Daß solche Beteuerungen durchaus Wirkung zeigten, bestätigte der französische Botschafter in Berlin, François-Poncet, am 25. November. In der französischen Öffentlichkeit bereite sich ein Meinungsumschwung vor, der auf die mehrfachen Friedenserklärungen des Kanzlers zurückzuführen sei, ließ er Hitler wissen ${ }^{31}$. Dergestalt ermutigt, blieb Ribbentrop auch nach dem Sturz des Kabinetts Daladier aktiv. Bei zwei Unterredungen mit Außenminister Louis Barthou am 4. März ${ }^{32}$ und am 16. Juni $1934^{33}$ warb er wiederum um ein „Regime des Vertrauens und der Zusammenarbeit" - mit mäßigem Erfolg. Barthou, der die Sicherheit seines Landes durch das wiedererstarkende Deutsche Reich gefährdet sah, lehnte Gespräche mit der Regierung Hitler zwar nicht rundweg ab, ließ sich aber, sehr zum Mißfallen Ribbentrops, nicht davon abbringen, ein Bündnis mit der Sowjetunion zu schmieden ${ }^{34}$.

Frankreichs friedensbewegte Frontkämpfer hatte Ribbentrop schon 1933, ein Jahr vor der Abetz-Initiative, als potentielle Zielgruppe nationalsozialistischer Einflußnahme ausgespäht, ebenso einen Mann, der wie kein zweiter geeignet schien, die nach der ,Machtergreifung" unterbrochenen Kontakte zwischen ihnen und den deutschen Kriegsopfervereinigungen neu zu knüpfen: Paul H. Distelbarth. 1879 als Sohn württembergischer Eltern in Böhmen geboren, war der gelernte Kaufmann bis 1914 gemeinsam mit seinem Vater in der Gablonzer Glaswaren-Industrie tätig gewesen. Ein längerer Aufenthalt in Paris im Jahre 1900 weckte sein nie mehr erlahmendes Interesse an Frankreich. Nach dem an der Ostfront

30 Das Interview wurde am 22. 11. 1933 in Le Matin, tags darauf im Völkischen Beobachter veröffentlicht. Auszüge bei Domarus, Hitler, I, S. $332 \mathrm{ff}$, und v. Schramm, ...sprich vom Frieden, S. $40 \mathrm{ff}$. Brinon schildert Einzelheiten des Gesprächs in seinem Buch France-Allemagne 1918-1934, Kap. XIX. Er diente das Interview Le Matin an, um eine größere Verbreitung sicherzustellen; sein Hausblatt L'Information erreichte damals nur eine bescheidene Auflage von 6000 Exemplaren. Inspection générale des services de police administrative, Bericht vom 25. 5. 1940: „Propagande allemande en France. Au sujet de M. de Brinon"; AN, 411 AP 6.

31 Aufzeichnung Neuraths vom 25. 11. 1933; ADAP, C II.1, S. 149.

32 Vgl. ADAP, C II.2, Nr. 301; DDF, 1, V, Nr. 463.

33 Vgl. ADAP, C III.1, Nr. 31; DDF, 1, VI, Nr. 356.

${ }^{34}$ Das erste Treffen vermittelte der Pariser Oberbürgermeister Jean de Castellane. Die zweite Zusammenkunft kam im Haus des Matin-Eigners Maurice Bunau-Varilla zustande, bei dem die NS-Propaganda stets offene Spalten fand. Léon Blum verspottete Le Matin deshalb als Pariser Ausgabe des Angriff; La Lumière, 14. 7. 1934. Zum „scharf gegen Deutschland akzentuierten " Kurs Barthous Mühle, Louis Barthou, S. 91 ff. Bezeichnend für die unkonventionellen Methoden Ribbentrops und seinen noch geringen Bekanntheitsgrad auch in deutschen Diplomatenkreisen ist ein Telegramm Kösters an das AA vom 6. 3. 1934: Barthou und „begreiflicherweise“ er selber bäten um „Aufklärung über Person und Funktion Ribbendrops [sic!]“; PA/AA, R 70545. Daß Ribbentrop mitnichten im Einklang mit dem Auswärtigen Amt handelte, war im Quai d'Orsay bekannt. Wie Botschafter François-Poncet von AA-Abteilungsleiter Köpke erfuhr, sei die Ernennung des Hitler-Vertrauten zum Abrüstungsbeauftragten der Reichsregierung in der Wilhelmstraße auf blankes Unverständnis gestoßen und eine Beleidigung für die Zunft („une injure pour la corporation"). Die deutschen Botschaften in Paris und London hätten sich schon wiederholt über Ribbentrops Aktivitäten beschwert, die sie weder kontrollieren noch korrigieren könnten. François-Poncet an Barthou, 26. 4. 1934; MAE, Europe 19181940, Allemagne 614. 
durchlittenen Ersten Weltkrieg erwarb er nahe Heilbronn ein Obst- und Weingut und engagierte sich für die vom Reichsbund der Kriegsbeschädigten und der Union fédérale initiierte CIAMAC ${ }^{35}$. Hieraus entwickelte sich zu Beginn der dreißiger Jahre eine enge Kooperation mit Robert Bosch. Der Stuttgarter Großindustrielle, Förderer der Paneuropa-Bewegung und der Deutsch-Französischen Gesellschaft, war naufs stärkste beeindruckt von der beweglichen Intensität des Mannes" und begriff die Annäherungsbestrebungen der ehemaligen Soldaten ebenfalls als verheißungsvollen Ansatz für eine breitenwirksame Verständigung „von unten her" 36 . Von Bosch protegiert und finanziell abgesichert, arbeitete Distelbarth bis 1933 intensiv am Ausbau der wechselseitigen Beziehungen ${ }^{37}$. Er bereiste die französische Provinz, mischte sich unter die Veteranen, aß an ihren Tischen, sprach auf ihren Versammlungen. Auch publizistisch kündete der überzeugte Pazifist hüben wie drüben vom Friedenswillen der Frontkämpfer (ohne deshalb - ebensowenig wie Abetz - für berechtigt gehaltene Revisionsansprüche hinsichtlich des Versailler Vertrags preiszugeben ${ }^{38}$ ). So erlangte er in beiden Ländern einen hohen Bekanntheitsgrad und pflegte „in allen französischen Kreisen glänzende Beziehungen“, wie DFG-Gründer Otto Grautoff anerkennend vermerkte ${ }^{39}$.

Diesen Mann wollte Ribbentrop für seine Zwecke einspannen. Am 28. Februar 1933 bestellte er Distelbarth ins Berliner Hotel „Kaiserhof“40. Der populäre Vermittler erläuterte die Vorteile einer Verständigung aus seiner Sicht und hielt ein Rapprochement für „durchaus möglich“, sofern man die Franzosen „auf greifbare Weise von der Aufrichtigkeit unserer Friedensliebe" überzeuge. Ribbentrop schien angetan; nach abschätzigen Bemerkungen über das "verniggerte" Nachbarvolk ließ er jedoch plötzlich in unerwartet krasser Manier die Maske fallen. Die neue Reichsregierung gedenke ohne Rücksicht auf Verluste aufzurüsten, um „bündnisfähig“ zu werden, belehrte er sein Gegenüber - „dann wollen wir uns gerne mit den Franzosen verständigen". Falls denen die Entwicklung nicht behage, sollten sie getrost Krieg anfangen, denn, so Ribbentrop mit menschenverachtendem Zynismus, „was kann es uns ausmachen, wenn wir zwei Millionen junger Leute opfern? Wir haben sowieso keine Arbeit für sie. Und wenn es die Franzosen auch vielleicht nur eine Million kostet, dann sind wir, bei ihrer geringen Geburtenzahl, immer noch die Gewinner!“

Damit war das Thema einer Zusammenarbeit für Distelbarth erledigt. Wenige Wochen später verdächtigte ihn die Geheimpolizei wegen seiner intensiven

35 Ein konziser Abriß seiner Biographie bei Bock, Paul Distelbarth und die „Verständigung von unten “. Siehe ferner Distelbarth, Kurzer Lebenslauf, abgedruckt in: Lendemains 18 (1993), Nr. 71/72, S. $95 \mathrm{f}$.

36 Vgl. Heuss, Robert Bosch, S. 529.

37 Über seine Mittlertätigkeit in der Zwischenkriegszeit ausführlich Bock, Konservativer Einzelgänger, S. 99-133.

$38 \mathrm{Vgl}$. Distelbarth, Neues Werden in Frankreich, S. 32.

39 Grautoff an Auswärtiges Amt, 25. 10. 1932; PA/AA, R 70554.

40 Das Folgende nach Distelbarths Erinnerungen: Wiedersehen mit Joachim v. Ribbentrop (ein Bericht von den Nürnberger Prozessen), in: Heilbronner Stimme, 13. 6. 1946; und ders., Franzosen und Deutsche, S. 170 f. 
Frankreichkontakte des Hochverrats und erließ Haftbefehl, dem er sich durch vorläufigen Verbleib in Paris entzog ${ }^{41}$. Seine "fanatische "42 Hingabe an die Verständigung und die außerordentlichen Sympathien, die er in französischen Veteranenkreisen genoß, paßten freilich zu perfekt ins Konzept der Hitlerschen Beschwichtigungskampagne, als daß die politische Verfolgung von Dauer gewesen wäre. Zudem setzten sich einflußreiche Franzosen für ihn ein, namhafte Frontkämpfer ebenso wie Daladiers Kabinettschef, der erklärte, solange solche Männer geächtet würden, könne seine Regierung unmöglich an die Aufrichtigkeit nationalsozialistischer Annäherungsversuche glauben ${ }^{43}$. Das Verfahren wurde eingestellt; Distelbarth konnte fortan unbehelligt zwischen Paris, wo er journalistisch tätig war, und seiner im schwäbischen Unterland gebliebenen Familie pendeln ${ }^{44}$. Weihnachten 1935 erschien im Rowohlt-Verlag sein vielbeachtetes, mit ideeller und materieller Unterstützung der Union fédérale geschriebenes Buch Lebendiges Frankreich, für damalige Verhältnisse ein Bestseller, bis 1939 fünfmal aufgelegt und auch ins Französische übersetzt ${ }^{45}$. Das Werk, eine auf eigenem Erleben basierende, von tiefer Zuneigung getragene Wesensbestimmung des französischen Volkes, in vielerlei Hinsicht eine Replik auf Sieburgs Gott in Frankreich?46, wollte zählebige Klischees und Vorurteile ausräumen und so zu einem friedlichen Miteinander beitragen. Gegen den Strom der nationalsozialistischen Publizistik schwimmend, die bevorzugt auf vermeintliche französische Schwächen abhob, porträtierte Distelbarth die ,Grande Nation' als ausgereiftes, lebenstüchtiges Staatsgebilde, das seine wahre Stärke aus der Provinz schöpfe und unter der turbulenten Oberfläche verblüffend homogen sei. Er scheute sich nicht, den Idealen von $1789 \mathrm{zu}$ huldigen ${ }^{47}$. Selbst deutsche Emigranten staunten über soviel Eigenständigkeit. Hermann Wendel fragte sich, ob das Buch tatsächlich aus „dem brau-

41 Ebenda, S. 172.

42 So Friedrich Sieburg in einer Rezension von Lebendiges Frankreich, in: Frankfurter Zeitung, 17. 3. 1936.

${ }^{43}$ Zit. bei Bock, Einzelgänger, S. 109. Um seinem bedrängten deutschen Freund zu helfen, wandte sich Pichot an das Außenministerium. Am 11. Mai 1933 antwortete Paul-Boncour: „Je vais bien volontiers faire mon possible en faveur de M. Paul Distelbarth, dont la situation est vraiment émouvante [...] Mais je crois que cela sera très difficile." AN, 43 AS 1, dr. 2.

44 Bock, Paul Distelbarth, S. 222; ders., Einzelgänger, S. 107 ff. Distelbarths Situation nach 1933 erscheint vor dem Hintergrund familiärer Bande, persönlicher Überzeugungen und gebotener taktischer Zurückhaltung einigermaßen kompliziert. Er will es nicht gewagt haben, „für dauernd nach Deutschland zurückzukehren, wo ich dem sicheren Untergang verfallen wäre" (Franzosen und Deutsche, S. 172). Kritischen Anmerkungen zum teils erzwungenen, teils selbstgewählten Exil in Frankreich von Geiger, Sympathie für den Feind?, S. 605, stellt Bock in seinen Arbeiten überzeugend das Porträt eines geradlinigen, um größtmögliche Unabhängigkeit bemühten, stets ehrlich für eine Besserung des deutsch-französischen Verhältnisses eintretenden Mannes gegenüber.

$45 \mathrm{Zu}$ Entstehung, Veröffentlichung und Rezeption Bock, Paul Distelbarths Lebendiges Frankreich, S. 99-113.

46 Siehe Margot Taureck, „Esprit“ und „Bonne volonté“ bei Friedrich Sieburg und Paul Distelbarth, in: Bock u. a. (Hrsg.), Entre Locarno et Vichy, I, S. 187-202.

47 Distelbarth, Lebendiges Frankreich, S. $217 \mathrm{ff}$. 
nen Berlin des Jahres 1936" stamme ${ }^{48}$. Die meisten Rezensenten im Reich zerrissen es aus ideologischen Gründen förmlich in der Luft. Einzig die überaus positive internationale Resonanz und der Umstand, daß ein Verbot einer „Selbstwiderlegung der nationalsozialistischen Verständigungsthetorik gleichgekommen “ wäre, sicherten die fortgesetzte Publikation eines Werkes, das erkennbar Züge „verdeckter Opposition“ gegen das Hitler-Regime trug49. Auch die DeutschFranzösischen Monatshefte, programmatisch dem Ausgleich verpflichtet, monierten spitz, man vermisse „den für uns unerläßlichen stolzen Willen, auch die französische Seite zum Verständnis, gerade des neuen Deutschland, zu führen" 50 . Distelbarth focht das nicht an. In seinem zweiten, 1938 veröffentlichten Buch Neues Werden in Frankreich schilderte er die im Reich gemeinhin als Ausgeburt des Bolschewismus verteufelte Volksfrontregierung als harmlosen Ausdruck eines verbreiteten Unwillens gegen den Einfluß der Hochfinanz und mochte allenfalls eine "marxistische Etikette" erkennen. Die eigentliche marxistische Doktrin sei französischem Wesen hingegen fremd ${ }^{51}$.

Solche interpretatorischen Freiräume duldeten die nationalsozialistischen Herrscher nicht ohne Hintergedanken. Distelbarths "blinde Verliebtheit", wie Kritiker seine Haltung zu Frankreich tadelten ${ }^{52}$, nützte ihnen insofern, als sie aus propagandistischen Gründen Wert darauf legten, sich dem Ausland als weltoffen und meinungsfreudig zu präsentieren. Der Autor stützte diese Absicht, wenn er schrieb, die durch sein Buch ausgelöste Diskussion und nicht zuletzt die Möglichkeit einer Neuauflage hätten bewiesen, "daß eine so heikle Frage, wie die deutschfranzösische, in Deutschland sehr wohl in voller Unabhängigkeit erörtert werden kann" 53 . Mit Feststellungen dieser Art, die wie lästige Konzessionen anmuten, ertrotzte er sich ein veritables Stück Meinungsfreiheit. Daß ihr zwangsläufig Grenzen gesetzt waren, dokumentiert der Hinweis an seine Leser, von Freimaurern, Juden und Emigranten sei deshalb keine Rede, „weil sie schlechterdings nicht zu den lebendigen Kräften des französischen Volkes gerechnet werden können"54. Gewissen Spielraum sicherte auch Distelbarths unverminderte Geltung bei den vom Hitler-Regime umworbenen Anciens combattants, denen er entscheidendes innenpolitisches Gewicht beimaß: Allein durch ihre Zahl seien sie eine große Macht, „die stärkste, die es in Frankreich gibt". Für bestimmte Ziele, etwa gegen einen mutwillig heraufbeschworenen Krieg, könne diese Masse leicht mobil gemacht werden: „keine Polizei, keine Truppe würde wagen, sich ihr in den Weg zu

48 Leo Parth (i.e. Hermann Wendel), „Lebendiges Frankreich“, in: Das Neue Tagebuch 15 (Jg. 1936), S. 354.

49 Bock, Distelbarths Lebendiges Frankreich, S. $109 \mathrm{ff}$.

50 Drei Bücher über Frankreich, in: DFM, Januar 1936, S. 24 (Hervorhebung im Original).

51 Distelbarth, Neues Werden, S. 27, $38 \mathrm{ff}$.

52 Vgl. Ewald Dolch, Lebendiges Frankreich?, in: Stuttgarter Neues Tagblatt, 11./12. 1. 1936. Der Rezensent rügte Distelbarths fehlendes ninneres Verhältnis“ zum Nationalsozialismus. „Man sieht, wo man auch das Buch aufschlägt, Voreingenommenheit für Frankreich und gegen Deutschland. Für den Verfasser ist die Uhr des Geschehens am 30. Januar 1933 stehengeblieben."

53 Lebendiges Frankreich, Vorwort zur 2. Aufl. (Oktober 1936), S. 3.

54 Ebenda, S. 2. 
stellen"55. Der auch im Reich überaus populäre Henri Pichot pries Lebendiges Frankreich in einem Vorwort als warmherzigen Versuch, "hineinzuleuchten in das deutsch-französische Mißverständnis, Quelle tragischer Konflikte“, der einzig erfolgverheißenden Richtschnur folgend, daß man einander kennen müsse, um sich verstehen und verständigen zu können ${ }^{56}$.

Am Fall Distelbarth wird deutlich, wie früh Ribbentrop danach trachtete, etablierte, massenwirksame deutsch-französische Gesellschaftsbeziehungen der Weimarer Zeit zu reaktivieren und damit einhergehend als Kanäle für die nationalsozialistische Paralleldiplomatie und Friedenspropaganda zu nutzen. Otto Abetz mit seinen in Eigeninitiative geknüpften Verbindungen zu französischen Frontkämpfern kam da wie gerufen, war allerdings, zumindest aus chronologischer Sicht, zweite Wahl - zuerst hatte sich Ribbentrop ja um Paul Distelbarth bemüht. Abetz' spontane Rekrutierung zum Frankreichreferenten, obwohl er für Ribbentrop ein gänzlich unbeschriebenes Blatt war, läßt ahnen, wie sehr Hitlers Sonderbotschafter nach Distelbarths Verweigerung geeignete Kontaktpersonen zum Neuaufbau zwischenstaatlicher Organisationsstrukturen fehlten ${ }^{57}$. Der karrierebewußte HJ-Mann war zwar ein Neuling auf dem Gebiet des Frontkämpfertums, dafür brachte er gleichsam als Mitgift exzellente Verbindungen zu anderen gruppenspezifischen Verständigungsbewegungen im Nachbarland - Jugendverbände und aufstrebende junge Intellektuelle - in sein neues Amt ein. Wie Distelbarth, von dessen Reputation bei den Anciens combattants er bei seinem Werben indirekt profitiert haben mag58, stand auch er als Repräsentant aussöhnungswilliger Kreise nach der nationalsozialistischen Machtübernahme am Scheideweg. Beider Engagement gründete auf der Maxime, neuen Feindseligkeiten durch vertrauenbildende gesellschaftliche Kontakte entgegenzuwirken. In der Folge aber wählten sie grundlegend verschiedene Ansätze, um ihre vor 1933 begonnene erfolgreiche Mittlertätigkeit im ,Dritten Reich fortführen zu können. Der spätere Herausgeber der Heilbronner Stimme demonstrierte, daß es möglich war, sich dem ideologischen Konformitätsdruck zu entziehen und selbst dann aktiv für alte Ziele einzutreten, wenn man sich treu und außerhalb des Machtapparats blieb. Letzteres hatte Abetz als aussichtslos erachtet - er setzte auf gestalterische Einflußnahme in Diensten des Regimes, kompromittierte sich mit dieser vermeintlichen Alternative jedoch rasch und gründlich. Distelbarth verachtete den „Renegaten der Jugendbewegung“ dafür aus tiefstem Herzen, schimpfte ihn „das widerlichste Pro-

\footnotetext{
55 Ebenda, S. 191.

56 Henri Pichot, „Dem deutschen Leser“, ebenda, S. 5, 7.

57 "Ich kann sagen, daß Herr von Ribbentrop ursprünglich mich für diesen Posten in Aussicht genommen hatte ${ }^{\text {“ }}$, bestätigte Distelbarth Robert Kempner. Vernehmungsprotokoll vom 11. 8. 1947; StA Nürnberg, KV-Anklage, Interrogations, D 34. Im Juli 1934 bemühte sich Ribbentrop vergeblich um eine erneute Unterredung mit Distelbarth; Bock, Einzelgänger, S. 108. Das Überraschungsmoment bei Abetz' Verpflichtung klingt in dessen Einlassung vor Gericht an. Er sprach von "diesem Zufall mit Ribbentrop“, der ihn "mit Beschlag belegt ${ }^{\alpha}$ habe. Abetz-Prozeß, 12. 7. 1949, pag. 15; AN, 334 AP 49.

58 Mit diesem Tenor Prost, Les anciens combattants français et l'Allemagne, S. 139.
} 
dukt von Schleim und Gallert, das es je gegeben hat" 59 . Vor propagandistischem Mißbrauch seiner Person war indessen auch er nicht gänzlich gefeit. Ungewollt hat er womöglich eine verhängnisvolle Entwicklung begünstigt: Indem er immer wieder die "unendliche Sehnsucht" der französischen Veteranen nach Frieden herausstellte und gleichzeitig ihren enormen Einfluß auf die Öffentlichkeit betonte ${ }^{60}$, gehörte er nach Einschätzung des Historikers und Zeitzeugen Gilbert Badia zu jenen, die Hitler zu der Auffassung verleiteten, die Franzosen würden eher jede beliebige Verletzung des Versailler Vertrags hinnehmen als einen neuen Krieg riskieren ${ }^{61}$.

\section{Außenpolitik durch Außenseiter: Mitarbeiter und Aufgaben der Dienststelle Ribbentrop}

Nicht allein seine ausgezeichneten Kontakte nach Frankreich machten Otto Abetz interessant für Ribbentrop, sondern zumindest unterschwellig auch der Umstand, daß er, an den Maßstäben der klassischen Diplomatie gemessen, ein AuBenseiter war. Deren gab es viele im ,Büro' des Sonderbotschafters, vom 1. Juni 1935 an ,Dienststelle' genannt, angefangen beim Chef selber. Offizierssohn Ribbentrop, Oberleutnant im Ersten Weltkrieg, Wein- und Spirituosen-Importeur, nicht zuletzt durch seine Heirat mit der Tochter des Sektfabrikanten Henkell zu ansehnlichem Wohlstand gelangt, bewirtete in seiner noblen Dahlemer Villa illustre Gäste aus Wirtschaft und Politik und bezeichnete sich als Anhänger der Deutschen Volkspartei, enthielt sich aber bis 1930 jeder aktiven politischen Betätigung ${ }^{62}$. Ein Regimentskamerad brachte ihn mit Hitler zusammen, den Ribbentrop mit Erzählungen über Auslandsaufenthalte beeindruckte. Für den ,Führer war er „in vieler Hinsicht der Mann von Welt, dessen Ansichten mit den seinigen oft überraschend übereinstimmten"63. Am 1. Mai 1932 trat Ribbentrop der NSDAP bei, von August an vermittelte er zwischen seinem langiährigen Bekannten v. Papen und Hitler, die über die Bildung einer "nationalen" Regierung verhandelten. Sein Anspruch, nach dem 30. Januar 1933 zum Staatssekretär des Aus-

59 Distelbarth, Deutsch-französische Verständigung, in: Heilbronner Stimme, 2. 11. 1946. Die gleichen Formulierungen in Franzosen und Deutsche, S. 174.

60 Vgl. ders., Lebendiges Frankreich, S. 185, 194, $201 \mathrm{ff}$.

61 Badia, La France vue par Paul Distelbarth: un pays modèle, in: Bock u.a. (Hrsg.), Entre Locarno et Vichy, I, S. 180. Im Oktober 1939 widersetzte sich Distelbarth dem Ansinnen des Reichspropagandaministers, im Rundfunk zu den französischen Kriegsteilnehmern zu sprechen. Während des Krieges lebte er zurückgezogen auf seinem Gut. Uber sein Wirken nach 1945 Bock, „Ich setze immer noch meine Hoffnung auf Frankreich“, in: Lendemains 18 (1993), Nr. 71/72, S. 64-89.

62 Michalka, Ribbentrop, S. 24ff.; Döscher, Das Auswärtige Amt im Dritten Reich, S. $146 \mathrm{ff}$. Vgl. Bloch, Ribbentrop, Kap. I; Weitz, Ribbentrop, Kap. 2-7.

63 Jacobsen, Außenpolitik, S. 259. Mehrfach bezeugt ist die Unterwürfigkeit Ribbentrops gegenüber Hitler, dem er meist eilfertig nach dem Munde zu reden pflegte. Der spätere Staatssekretär des AA, Baron Steengracht v. Moyland, sprach in Nürnberg von einer "gewissen hypnotischen Abhängigkeit“. Vernehmung Steengrachts am 26. 3. 1946; IMT, X, S. 127. 
wärtigen Amtes berufen zu werden, blieb unerfüllt. Papen bedeutete ihm, für diesen Posten werde ein Mann „von breitem Wissen und erprobten Fähigkeiten“ benötigt, ein Außenseiter käme dafür „am wenigsten in Betracht"64.

Um parteiintern an Gewicht zuzulegen, stieß Ribbentrop daraufhin zur SS, wo er von Himmler protegiert und rasch befördert wurde. Auch auf außenpolitischem Terrain konnte er seinem rastlosen Ehrgeiz bald freien Lauf lassen, als sich eine ganze Reihe neuer, nichtstaatlicher Stellen in die internationalen Beziehungen einzumischen begann ${ }^{65}$. Hitler selbst hat diese Entwicklung - wie auch in anderen Ressorts - gefördert, um Verwirrung zu stiften und machtpolitische Konkurrenten in Kompetenzstreitigkeiten zu verstricken ${ }^{66}$. Hinzu kam, daß er das konservative Beamtenkorps des AA für ein völlig ungeeignetes Instrument hielt, seine revolutionären Ziele zu verwirklichen. Noch immer müsse sich die Staatsführung gegen die Bürokratie im Lande durchsetzen, klagte er im November 1938 vor $D N B$-Vertretern; am schlimmsten herrsche sie im Auswärtigen Amt. Diplomaten alten Schlages seien nicht Vertreter ihrer Völker, sondern Angehörige einer internationalen Gesellschaftsklasse. Dieses Übel sei nicht von heute auf morgen abzustellen, es werde Jahre dauern, bis nationalsozialistisch geschulter Nachwuchs bereitstünde. Als bisher einzigen Mann des ,Dritten Reiches', der es verstanden habe, „im Ausland richtig aufzutreten und das neue Deutschland dort zu repräsentieren“, pries Hitler Ribbentrop, einen „Diplomat neuen Stils", der sich durch "Energie, Härte, Mut und Nerven" auszeichne ${ }^{67}$.

Der servile Streber avancierte 1934 nach inoffiziellen Missionen in Paris und London zum Beauftragten der Reichsregierung für Abrüstungsfragen. In dieser Eigenschaft bezog Ribbentrop Büroräume in der Berliner Wilhelmstraße und sah sich nach Mitarbeitern um. Selber ein Amateur, galten ihm die gestrengen Kriterien, die Anwärter für den Auswärtigen Dienst erfüllen mußten, herzlich wenig. Er suchte seine Angestellten vielmehr danach aus, „ob sie ihm aufgrund ihrer Beziehungen im zwischenstaatlichen Verkehr persönlich nützlich sein konnten, in der Partei anerkannt wurden oder entsprechend seinen eigenen Vorstellungen Initiative entwickeln würden"68. Dieses Anforderungsprofil wurde umgehend zum Programm erhoben, aus weltanschaulicher Überzeugung wie aus Gründen der Selbstlegitimation. Jeder „Volksgenosse“ müsse ungeachtet seiner Herkunft die Chance erhalten, seine Befähigung zur diplomatischen Laufbahn durch Leistungen und Charakter nachzuweisen, forderte ein Memorandenschreiber der ,Dienststelle', der ein „Nachwuchshaus deutscher Diplomaten“ projektierte. Bewerber sollten willensstark, unternehmungslustig, verantwortungsfreudig und von "klaren nationalsozialistischen Grundsätzen“ geleitet sein, sich „von frucht-

64 v. Papen, Der Wahrheit eine Gasse, S. 421.

65 Neben der ,Dienststelle' vor allem: Auslandsorganisation der NSDAP (AO), Außenpolitisches Amt der NSDAP (APA), Volksdeutscher Rat, Reichsministerium für Volksaufklärung und Propaganda, SS/SD.

66 Dazu ausführlich Jacobsen, Zur Struktur der NS-Außenpolitik, in: Funke (Hrsg.), Hitler, S. 137-185.

67 Aufzeichnung Likus vom 11.11. 1938 über Hitlers Auftritt vor der deutschen Presse am Vortag in München; PA/AA, R 27091.

68 Jacobsen, Außenpolitik, S. 267. 
loser Theorie fernhalten“ und statt dessen durch „dauernde persönliche Fühlungnahme mit allen Schichten und Berufen [...] im In- und Ausland" ein wirklichkeitsnahes Weltbild entwickeln. Bar jeder Eitelkeit müßten sie Erfolge des ,Führers' als größtmögliche Anerkennung ihrer Arbeit werten ${ }^{69}$.

Die ,Dienststelle' spezialisierte sich auf zwischenstaatliche Kontaktpflege. Den Kern bildeten die Referate „Frankreich“, „England“, „Osten“ und „Volkstum/ Frontkämpfer“. Die Mitarbeiter waren gehalten, Deutschlands internationales Ansehen zu mehren und ihren Chef rund um die Uhr mit aktuellen Informationen zu versorgen. Alles drehte sich darum, persönliche Beziehungen zu Angehörigen anderer Staaten aufzubauen und bei Bedarf spielen zu lassen, die Stimmung zugunsten des ,Dritten Reiches' zu beeinflussen und feindseliger Propaganda entgegenzuwirken. Fremdsprachenkenntnisse und Auslandserfahrung waren erwünscht, ein gewinnendes Auftreten oberstes Gebot. „Die Leute aus Ribbentrops Umgebung gefallen denen, die mit ihnen zu tun bekommen", notierte Italiens Außenminister Ciano. „Es sind nicht die üblichen hölzernen deutschen Knoten, [...] sondern sympathische Jünglinge, welche fremde Sprachen gut sprechen und gelernt haben, eine Dame im Salon höflich zu behandeln, anstatt mit den Absätzen zu knallen. "70 Unter solchen Prämissen fiel die Wahl unter anderem auf Wilhelm Rodde, der eine Kaufmannslehre in New York absolviert und zeitweise in Brasilien gelebt hatte; auf den Psychologie-Professor Karlfried Graf v. DürckheimMontmartin, der im Anschluß an einen Erzieher-Kongreß in Südafrika einen Bericht zur Lage des Deutschtums am Kap verfaßte; auf Dr. Hermann v. Raumer, ehemaliger Lufthanseat und überzeugter Antibolschewist; auf die ,alten Kämpfer Rudolf Likus und Walther Hewel, die Ribbentrops kümmerliche Hausmacht in der Partei aufpolieren sollten. Die Beispiele ließen sich fortsetzen ${ }^{71}$.

In diesem heterogenen Kreis - ins Auge stechen das geringe Alter, die akademische Bildung und die große Auslandserfahrung zahlreicher Mitglieder - war die Zugehörigkeit zur NSDAP zunächst nicht zwingend erforderlich, der Beitritt zur SS ganz offensichtlich erwünscht ${ }^{72}$, in jedem Fall aber Platz für Männer vom Schlage eines Otto Abetz. Anläßlich seiner Ernennung zum Botschafter im August 1940 feierte ihn die NS-Propaganda als Vorbild für jenen neuen Diplomatentypus, den Ribbentrop heranzüchten wollte. Daß er nicht die übliche Karriere durchlaufen habe, werde „vielen, die sich mit der Entwicklung der Diplomatie be-

${ }^{69}$ Denkschrift „Zweck und Ziel des Nachwuchshauses junger deutscher Diplomaten“, ohne Datum, unsig.; PA/AA, R 27188.

70 Ciano, Tagebücher 1939-1943, S. 86f. (Eintrag am 7. 5. 1939).

71 Ein ausführlicher Überblick mit Kurzbiographien der wichtigsten Mitarbeiter bei Jacobsen, Außenpolitik, S. $268 \mathrm{ff}$.

72 Nach Abetz' Darstellung waren für die Mitarbeiter von Ribbentrop, der zur Absicherung seiner Position Anlehnung an die Schutzstaffel suchte, SS-Ränge obligatorisch. Vgl. Verhörprotokoll Nr. 204/4; AN, F 7/15331. Er selbst trat zum 1. 8. 1935 ein (Dienstgrad SSMann, SS-Nr. 253314), wurde zunächst im RFSS Stab, vom 13. 9. 1936 an beim SS-Hauptamt geführt. Die letzte Beförderung, zum Brigadeführer, datiert vom 30. 1. 1942. Übersichtsblatt „Dienstlaufbahn“, SS-Stammrollen-Auszug vom 21.7. 1937; BDC/Abetz. Unzutreffend seine Behauptung, nie den Treueid geleistet zu haben (Vernehmung durch John Fried 1947, StA Nürnberg, KV-Anklage, Interrogations, A 2); laut Stammrollen-Auszug geschah dies am 11.2. 1936. 
faßt haben, als ein Wendepunkt erscheinen, der unvermeidbar kommen mußte", schrieb sein mit Frontkämpferfragen betrauter Kollege Heinrich Georg Stahmer im Entwurf eines geplanten Presseartikels über Abetz. „Diplomatie ist nicht mehr eine Angelegenheit einer besonderen Menschenklasse, die durch Vermögen oder Namen sich für diese Tätigkeit allein berechtigt hält, sondern eine Frage der Eignung und der für diesen Beruf nötigen Fähigkeiten, wie Menschenkenntnis im allgemeinen und Kenntnis der Mentalität der verschiedenen Völker im besonderen. "73 Tatsächlich vermittelte seine Tätigkeit Abetz das beglückende Gefühl, zu einer den alten Diplomaten überlegenen Avantgarde zu gehören, die mutig neue Wege beschritt - hatte er das nicht schon Ende der zwanziger Jahre getan, als er das Sohlbergtreffen organisierte? Ebenso nostalgieverbrämt wie selbstbewußt kontrastiert er in seinen Memoiren den Typus des angegrauten AA-Theoretikers, der über eine akribisch genaue Lagebeurteilung selten hinauskommt, mit den jungen Aktivisten der ,Dienststelle', die nicht lockerlassen, bis sich die internationalen Beziehungen gemäß dem Reichsinteresse entwickelt haben. „Hier ein unbestreitbares Übergewicht an Fachwissen, an Kenntnis der Geschichte [...] Dort eine lebensnähere Verbindung mit den Menschen und Mächten, die das gegenwärtige politische Bild und Streben des ausländischen Volkes bestimmten." 74 Nach Darstellung des langjährigen Pariser Botschaftsmitglieds Feihl haben Ribbentrops Gefolgsleute dieses Elitebewußtsein geradezu verinnerlicht: „Pour ces jeunes gens [...], nous étions tous des vieilles barbes." 75

Die unkonventionellen, großzügigen Arbeitsbedingungen in der rasch expandierenden ,Dienststelle', die 1936/37 weit über 100 Mitarbeiter zählte, motivierten Abetz. Er verfügte über ausreichende Geldmittel, konnte auf Antrag jederzeit ins Ausland reisen und bei Bedarf sogar ein bereitstehendes Flugzeug benutzen. $\mathrm{Zu}$ den operativen Möglichkeiten gesellte sich, den Blick weiter verengend, ein dem äußeren Anschein nach einem liberalen Führungsstil verpflichteter Korpsgeist, den Ribbentrop seinem Team als unerläßlich für "bestimmte Spezialaufgaben" einimpfte. Seine Vorgabe war "eine Kameradschaft, die ihre Aufgaben von der Führung bekommt, und in der jeder sein Stückchen Selbständigkeit hat [...], ohne nach scharfen Richtlinien oder sonstigen Dingen zu sehen". Gleichzeitig betonte er, die Reichsregierung wünsche inniglich Frieden, und appellierte an seinen Stab, „alles daran zu setzen, daß diesem Geist des Führers überall draußen Eingang verschafft wird"76. Solche Rahmenbedingungen waren zweifellos geeignet, den Blick dafür zu trüben, wie es um die deutsche Frankreichpolitik wirklich bestellt war. Seine Zufriedenheit über vermeintliche Möglichkeiten, die Aussöhnung voranzutreiben, mußte Abetz die Einsicht erschweren, daß skrupellose Machthaber ihn als Werkzeug mißbrauchten. Ribbentrop machte es ihm leicht, von der Friedfer-

73 „Botschafter Otto Abetz“, Entwurf mit Anschreiben Stahmers an Abetz (Paris) vom 11. 8. 1940; PA/AA, Personalakte Abetz/1. Dieser Entwurf bildete offenkundig auch die Grundlage eines Beitrags im Giornale d'Italia am 13.11. 1940, „Nuovi diplomatici per la grande Germania“.

74 Abetz, Das offene Problem, S. 48f.

75 Aussage Feihls im Abetz-Prozeß, 19. 7. 1949, pag. 51; AN, 334 AP 49.

76 "Rede des Botschafters [Ribbentrop] auf der Weihnachtsfeier im ,Kaiserhof" 1936“; PA/ AA, R 27183. 
tigkeit der NS-Führung zu künden. „Sie können in meinem Namen jede der deutsch-französischen Verständigung dienende Initiative ergreifen und fördern“, instruierte er Abetz' Erinnerungen zufolge den begeisterungsfähigen Novizen. „Auch mir ginge ein alter [...] Wunsch in Erfüllung, wenn die zwei großen europäischen Kulturnationen zu guten Nachbarn werden könnten. "77 Abetz interpretierte diese Worte als Blankovollmacht, von der er ausgiebig Gebrauch machen wollte.

\section{Kredit für die deutsche Friedenspropaganda: Jean Goy und Henri Pichot bei Hitler}

Schon im Oktober 1934 reisten Abetz und Oberlindober, jetzt mit ausdrücklicher Billigung Ribbentrops, in Erwiderung des Pichot-Besuches nach Paris. Die Gespräche im „Maison de l'Union fédérale“ - Hauptthema war das für Januar 1935 vorgesehene Plebiszit zur Zukunft des Saarlandes - gelangten jedoch rasch an einen toten Punkt. Pichot störte, daß seine Gäste gebetsmühlenartig Hitlers Standpunkte wiederholten: "Leurs phrases essentielles sont comme stéréotypées." Ihrem Vorschlag, im Vorfeld der Saarabstimmung eine gemischte Überwachungskommission aus Frontkämpfern beider Länder zu bilden, räumte er nur geringe Chancen ein ${ }^{78}$. Anlaß zu dieser Offerte gaben hartnäckige Gerüchte über einen drohenden nationalsozialistischen Putsch an der Saar und angebliche französische Präventivschläge. Beide Seiten verdächtigten einander, eine freie, geheime Abstimmung sabotieren zu wollen. Jede Eskalation aber gefährdete den internationalen Prestigegewinn, den sich die Reichsregierung von einem eindeutigen Bekenntnis der Saarbevölkerung zu Deutschland erhoffte. Wiederholte Beteuerungen, nach der Rückkehr des kraft Versailler Vertrags abgetrennten Landstrichs bestünden keinerlei territoriale Forderungen mehr gegen Frankreich, vermochten die Wogen nicht zu glätten. Im Kreise der NS-Führung sann man deshalb auf zusätzliche Mittel und Kanäle, Befürchtungen eines gewaltsamen deutschen Vorgehens zu zerstreuen 79 .

Auch an Jules Romains, der am 12. November auf Einladung des Sohlbergkreises in Berlin über "Latinität und Germanentum" referierte und während seines Aufenthalts in der Reichshauptstadt etliche Nazigrößen traf ${ }^{80}$, wurde der Kommissionsgedanke herangetragen. Alfred Rosenberg betonte, ein regierungsamtliches Aufsichtsmandat für deutsche und französische Veteranen - „Männer mit Selbstkontrolle“ - sei „eine Bürgschaft für Unparteilichkeit" und garantiere Ruhe und Ordnung an der Saar. Goebbels wollte eine solche Maßnahme "mit Freuden“ begrüßen. Romains vermochte keinen „Fallstrick“ zu erkennen; ihn begeisterte

77 Zit. bei Abetz, Das offene Problem, S. 51.

78 Pichot, Et ce fut quand même la guerre, pag. $17 \mathrm{f}$.

79 Das Auswärtige Amt mahnte seit Monaten, jede Provokation zu unterlassen. Vgl. ADAP, C III.1, Nr. 242, 281, 283; III.2, Nr. 290, 307, 311, 314, 320.

80 Jules Romains à Berlin, in: DFM, Dezember 1934, S. 80 f. Sein Vortrag in deutscher Übersetzung im selben Heft, S. 47-63. 
die Vorstellung, daß „einige der besten Elemente“ beider Völker in "ritterlicher Weise" zusammenarbeiten würden. So gelobte er, sich für den Kommissionsplan zu verwenden, dessen geistige Urheberschaft er Abetz zuschrieb. Dieser habe seine Idee klugerweise nicht nur Ribbentrop mitgeteilt, sondern sie auch im Umfeld der Konkurrenten Rosenberg und Goebbels ventiliert, um die Erfolgsaussichten zu verbessern und zugleich allen Parteien das schmeichelhafte Gefühl zu geben, die Initiative ergriffen zu haben. Zurück in Paris, warb der Schriftsteller in einer Rede an der Sorbonne, bei Frontkämpferfunktionären und im Quai d'Orsay für das Projekt. Alexis Léger ließ ihn mit „sanfter Störrigkeit“ abblitzen, während Außenminister Laval eine genauere Prüfung zusagte. Auf Beschluß des Völkerbundrates vom 12. Dezember überwachte schließlich ein 3000 Mann starkes internationales Truppenkontingent, gebildet aus Briten, Italienern, Schweden und Holländern, die Abstimmung, in Romains' Augen immerhin ein halber Sieg, wobei allerdings die "psychologischen und moralischen Vorzüge" der Frontkämpferlösung verschenkt worden seien ${ }^{81}$.

Vor dem Hintergrund der Saarkrise und den deutschen Bemühungen, sie aus taktischen Gründen zu entschärfen, ist ein weiterer Anlauf Abetz' bei Henri Pichot zu sehen. Ende Oktober kreuzte er unangemeldet in Orléans auf und bekniete den Franzosen, unverzüglich mitzukommen und Hitlers Vorschläge anzuhören. Doch Pichot zierte sich erneut, fühlte sich überrumpelt und verlangte mehr Vorbereitungszeit ${ }^{82}$. Zweifellos bremste ihn die Ungewißheit, wie eine solche Mission, die noch nicht einmal von seinem Verband abgesegnet war, in Frankreich aufgenommen würde. Schon bald durfte er sich in seiner Vorsicht bestätigt sehen. Abetz reiste unzufrieden ab, hatte dann aber mit seinen Bemühungen, prominente Veteranen nach Berlin zu locken, unverhofft Glück bei der Konkurrenz: Jean Goy, konservativer Parlamentarier für das Seine-Département und Vizepräsident der Union nationale, willigte ein, in die Reichshauptstadt zu kommen, desgleichen Robert Monnier, Stadtverordneter von Paris und führendes Mitglied der Semaine du combattant. Im Urteil de Jouvenels gelang Abetz damit ein „Meisterstück“83. Eine überraschende Entwicklung war es allemal, da beide Verbände die Chancen eines deutsch-französischen Ausgleichs in der Vergangenheit skeptisch beurteilt hatten ${ }^{84}$. Der aus der Auvergne stammende Goy, im Vorstand eines großen Pariser

81 Nach Romains, The Mystery of Ribbentrop \& Co., in: The Saturday Evening Post, 16. 11. 1940; deutsche Übersetzung bei den Akten der Dienststelle Ribbentrop; PA/A'A, R 27159. Auch Jean Goy, führendes Mitglied der UNC, äußerte sich positiv über den Kommissionsgedanken; Le Petit Journal, 30.11.1934. Vgl. Das Archiv, November-Dezember 1934, S. 1239 f.

82 Pichot, Et ce fut quand même la guerre, pag. $18 \mathrm{f}$.

83 Jouvenel, Voyageur, S. 202.

84 Vgl. Prost, Les anciens combattants, I, S. 106. Distelbarth, Lebendiges Frankreich, S. 190, schildert Goy als "bis dahin ausgesprochen deutschfeindlich“. Jouvenel, S. 203, spricht von einer "Kehrtwende“. Botschafter v. Hoesch verzeichnete im März 1930 immerhin eine Milderung der „ursprünglich nationalistischen Tendenzen“ bei der UNC, verbunden mit dem Rücktritt stramm rechtsgerichteter Führer. „Neuerdings [...] hat sich eine Mehrheit für die Politik der Verständigung ausgesprochen “; Hoesch, „Übersicht über französische Kriegsteilnehmerorganisationen" vom 7. 3. 1930; PA/AA, R 70536. Den DDF-Editoren zufolge wurden Goy und Monnier begleitet von Jean Desbons von der Vereinigung 
Maschinenbaukonzerns tätig, hatte allerdings am 18. September im Petit Journal Gesprächsbereitschaft signalisiert und eine starr germanophobe Haltung als unproduktiv und töricht bezeichnet. Die jüngsten Erklärungen von Hitler und $\mathrm{He} ß$ dürften nicht einfach ignoriert werden, sie eröffneten Chancen für einen dauerhaften Frieden und gehörten deshalb ausgelotet ${ }^{85}$. Daß ein gütliches Auskommen mit anderen Nationen unabhängig von den dort herrschenden politischen Systemen anzustreben sei, hatte die UNC schon in einem Manifest vom Oktober 1933 betont ${ }^{86}$.

Hitler empfing Goy und Monnier am 2. November 1934 in Anwesenheit von Ribbentrop, Oberlindober und Heß; letzterer hatte wenige Tage nach seiner Königsberger Rede in einem Interview des Petit Journal noch einmal Notwendigkeit und wirtschaftliche Signalwirkung eines Rapprochements betont und eine aktive Unterstützung des Annäherungsprozesses durch die französischen Anciens combattants für unerläßlich erklärt, weil sie mehr Verständnis für die deutschen Gleichberechtigungsforderungen aufbrächten als irgend jemand sonst ${ }^{87}$. Abetz dolmetschte und konnte den ,Führer' erstmals aus der Nähe beobachten. Er registrierte ein gepflegtes Äußeres, vermißte „klare Winkel und Linien“ im Gesicht. Faszinierend fand er Hitlers Augen - „von einem ungewöhnlichen suggestiven Blau" - und die „sparsamen, aber ungemein ausdrucksvollen Gesten“ der "feinnervigen, schmalen Hände“. Im Mienenspiel des Kanzlers entdeckte er "nichts [...], was ein persönliches menschliches Interesse an seinen französischen Gästen verraten hätte, aber auch nichts, was den Rückschluß auf versteckte Hintergedanken erlaubte" 88 . Der Termin schien mit Bedacht gewählt - Allerseelen war ein denkbar geeigneter Tag, um an die Millionen Kriegsopfer zu erinnern und für gutnachbarliche Beziehungen zu werben ${ }^{89}$. Hitler hob zielsicher auf das Selbstverständnis seiner Besucher $a b$, indem er betonte, gerade Kriegsveteranen seien es gewohnt, Schwierigkeiten offen anzupacken. Ohne Rücksicht auf diplomatische Gepflogenheiten müßten sie einander ihre Besorgnisse mitteilen, um so drohende Konflikte rechtzeitig zu entschärfen. Er wünschte ein Ende des Wettrüstens auf dem Wege bilateraler Verhandlungen und malte den Gästen aus, wie sehr eine deutsch-französische Aussöhnung in ganz Europa als Ende eines Alpdrucks empfunden, wie sehr sie Psyche und wirtschaftlichen Unternehmungsgeist der Völker beflügeln würde. „Von unseren beiden Völkern hängt es ab, daß dieser Traum verwirklicht wird." Mein Kampf tat er wie üblich als inhaltlich längst überwundene

Prisonniers de guerre; DDF, 1, VIII, S. 13, Anm. 3; in keinem der ausgewerteten Berichte aber wird sein Name erwähnt.

85 Luchaire, „Une explication franco-allemande est devenue possible, nécessaire“ affirme $M$. Jean Goy, am 19. September abgedruckt in Notre Temps. Hierzu Köster an Auswärtiges Amt, 22. 9. 1934; PA/AA, R 70556.

86 Zit. bei Prost, Les anciens combattants (1914-1939), S. $223 \mathrm{ff}$.

${ }^{87}$ „M. Rudolf Hess porte-parole d'Hitler. Celui qui demain sera peut-être vice-chancelier compte pour éviter la catastrophe sur les anciens combattants ${ }^{\text {, }}$, in: Le Petit Journal, 5. 8. 1934. Das Gespräch mit Heß führte Stanislas de La Rochefoucauld.

88 Abetz, Das offene Problem, S. 53.

${ }^{89}$ Schulthess' 1934, S. 260 f.; Das Archiv, November-Dezember 1934, S. 1247 f. FrançoisPoncet an Laval, 3. 11. 1934; DDF, 1, VIII, Nr. 11. Domarus, Hitler, I, S. 460 f. 
Philippika vergangener Tage ab. Die Reichsregierung denke nicht an zu erobernde Quadratkilometer, sondern konzentriere sich auf die Verwirklichung einer neuen sozialen Ordnung und die Sicherung des Friedens. Er verneinte ausdrücklich deutsche Ambitionen auf Elsaß-Lothringen und dementierte, zur aktuellen Tagespolitik überschwenkend, Putschvorbereitungen an der Saar. Es sei ,reine Torheit“ zu glauben, daß Deutschland durch Gewaltanwendung das Plebiszit stören wollte. In Erwartung von Goys Besuch habe er einen Befehl vorbereitet, der in einer 40 Kilometer breiten Zone entlang der saarländischen Grenze Aufmärsche uniformierter SA- und SS-Einheiten verbiete ${ }^{90}$. Im übrigen werde man sich „dem Ergebnis der Volksabstimmung, gleichviel wie sie ausfällt, beugen“"

Oberlindober, der hernach zu einem Frühstück lud, beobachtete, daß Hitlers Ausführungen „starken Eindruck“ gemacht hatten. Die Gäste äußerten den Wunsch, politisch zu einer Entspannung beizutragen, regten eine organisatorische Verankerung der Kontakte zu ihren deutschen Kameraden an und empfahlen eine „beruhigende gemeinsame Erklärung "91. Optimistisch gestimmt fuhren Goy und Monnier nach Hause - die Reichsregierung schien tatsächlich gute Absichten zu hegen. In diesem Sinn informierte Goy Kriegsminister Pétain, der darum bat, den Berliner Regierenden „auf sein Manneswort“ auszurichten, daß auch Frankreich die Saarfrage friedlich zu lösen gedenke. Außenminister Laval gelobte dasselbe ${ }^{92}$, und die Tageszeitung Le Matin berichtete am 18. November groß über die Deutschlandreise der Veteranen; der regierungsnahe Petit Parisien hatte zuvor abgelehnt ${ }^{93}$. Das Echo in Frankreich war gespalten. Kaum jemand traute der nationalsozialistischen Verständigungsofferte ohne Vorbehalt, wie ein Blick in die Pariser Tagespresse zeigt ${ }^{94}$. Wohlwollend urteilten allein linkspazifistische Blätter wie L'Euvre, dessen Leitartikler die Völkerverständigung zum überparteilichen Ziel erhob und den rechten Abgeordneten Goy uneingeschränkter Solidarität versicherte (20.11.). La Victoire-Direktor Gustave Hervé, dem Frontkämpfermilieu verbunden, mochte an Hitlers Aufrichtigkeit nicht zweifeln; der Diktator sei gewiß ein fanatischer, zur Gewalt fähiger Hitzkopf, aber kein Intrigant und

90 Bericht Goys auf der Generalversammlung der UNC-Sektion Vincennes am 21. November: „Pourquoi Jean Goy a-t-il rencontré Hitler?“, in: La Tribune Cantonale, 25. 11. 1934. Der Saarbevollmächtigte der Reichsregierung, Gauleiter Bürckel, richtete am selben Tag, da Goy und Monnier bei Hitler weilten, ein entsprechendes Verdikt an SA und SS des Saargrenzgebiets. Ihre Aktivitäten sollten vom 10. Januar bis 10. Februar 1935 ruhen. Auch im Foreign Office war man hierüber zufrieden. Vgl. Simon an Phipps (Berlin), 5. 11. 1934; DBFP, 2, XII, Nr. 169. Am 6. Dezember - eine weitere taktisch bedingte Konzession - wurde allen SA- und SS-Angehörigen, soweit sie nicht abstimmungsberechtigt waren, die Einreise ins Saargebiet untersagt. Das Archiv, November-Dezember 1934, S. 1234f., 1240. Abetz, Das offene Problem, S. 54, datiert die Ankündigung der Maßnahme irrtümlich auf den Empfangstermin Pichots bei Hitler.

91 Aufzeichnung des Vortragenden Legationsrats v. Rintelen (AA), 12.11. 1934; ADAP, C III.2, Nr. 321.

92 Hoesch (London) an Auswärtiges Amt, 8. 11. 1934, mit Bezug auf ein Telegramm Ribbentrops; ebenda, Nr. 311. Zum Kalkül der französischen Diplomatie in dieser Phase Mühle, Frankreich und Hitler, S. 328.

93 Bericht der Sûreté Nationale vom 7. 12. 1934; AN, F 7/13433.

94 Die folgenden Beispiele sind Pressespiegeln im DNB-Rohmaterial vom 19. und 21.11. 1934 entnommen; PA/AA, R 70556. 
Heuchler (19. 11.). Politisch gemäßigte Journalisten vernahmen des Kanzlers Kunde wohl, wollten sie freilich gern durch Taten bestätigt sehen (L'Intransigeant, La République, 19. 11.). Der Rest war schiere Kritik. Viele Kommentatoren argwöhnten, Goy und Monnier hätten sich für ein billiges Propagandamanöver im Vorfeld der Saarabstimmung einspannen lassen; Gewerkschaftsgazetten und die kommunistische L'Humanité (19.11.) nannten sie unverblümt „Hitler-Agenten". Rechtsorientierte Zeitungen zitierten Passagen aus Mein Kamp $f$ und ziehen die Berlinfahrer blinder Vertrauensseligkeit, ja Gefühlsduselei. Wie könne man so naiv sein, wunderte sich L'Ordre (19.11.), dieser Sprache auch nur einen Funken Glauben zu schenken. Die Deutschen seien als professionelle Lügner weltbekannt, ereiferte sich die ultranationalistische Action Française (19.11.), während das konservative Journal des Débats an die militante Intoleranz des NS-Regimes gegen Andersdenkende erinnerte und - nicht zu Unrecht - einen raffinierten Schachzug witterte, der Teil einer Strategie sei, die Westmächte von Verteidigungsmaßnahmen abzuhalten, während Deutschland sein Angriffsinstrument schmiede (19./21.11.).

Zusätzliches Mißtrauen weckte der Umstand, daß deutsche Zeitungen bis zum 24. November nichts über die Frontkämpfer-Audienz bei Hitler berichteten. Wurden seine Erklärungen der eigenen Bevölkerung etwa bewußt vorenthalten? Erst nach besorgten Meldungen der Botschaft Paris, die Nachrichtensperre nähre Zweifel an Hitlers Glaubwürdigkeit und schmälere die Wirkung seiner Worte, wurden entsprechende Weisungen an die deutsche Presse korrigiert ${ }^{95}$. Über den vertraulichen Empfang in der Reichskanzlei „sollte abredegemäß nichts erscheinen“, behauptete Staatssekretär v. Bülow; Hitlers Standpunkt sei der deutschen Öffentlichkeit im übrigen hinlänglich bekannt ${ }^{96}$. „Wozu der Lärm?“ fragte demzufolge die Berliner Börsenzeitung (24.11.), und die gleichgeschaltete Journaille im Reich verbreitete die offizielle Begründung des Auswärtigen Amts, nicht ohne den kritischen Pariser Kollegen Beckmesserei, ja Sabotage am Verständigungsprozeß vorzuwerfen.

Auch innerhalb seines Verbandes wurde Jean Goy hart angegangen. UNCChef Georges Lebecq erklärte, sein Vize habe ohne Auftrag gehandelt, und entzog ihm kurzerhand das Vertrauen ${ }^{97}$. Die antifaschistische Ligue des anciens combattants pacifistes forderte die Aufhebung seiner parlamentarischen Immunität und die Einsetzung eines Untersuchungsausschusses. Ihren Verantwortlichen wollte nicht in den Kopf, wie ein Mann, der so oft Kontakte zu den ehemaligen Feinden abgelehnt hatte, nun Shake-hands mit dem „Henker des deutschen Volkes“ machen und ihn als Friedensapostel präsentieren könne ${ }^{98}$. Die Proteste kulminierten

95 Forster (Paris) an Auswärtiges Amt, 21. 11. 1934; PA/AA, R 70556. NS-Presseanweisungen der Vorkriegszeit, hrsg. von Hans Bohrmann, 2, S. 515.

96 Bülow an Botschaft Paris, 22. 11. 1934; PA/AA, R 70556. Goy behauptete, ausgehandelt zu haben, daß ihm allein die Entscheidung über eine Bekanntgabe des Gesprächsinhalts überlassen bliebe. Bericht des Deutschen Generalkonsulats Marseille vom 12.12. 1934 über einen öffentlichen Vortrag Goys, ebenda.

97 Prost, Anciens combattants, I, S. 178.

98 Bericht der Sûreté Nationale vom 1.12. 1934 mit Rundschreiben der Ligue; AN, F 7/ 13433. Goy wurden faschistische Neigungen nachgesagt. Vorwürfe, es sei ihm vielleicht 
in einer erregten Kammerdebatte zur außenpolitischen Lage am 30. November. Unter teilweise lebhaftem Beifall quer durch die Fraktionen verneinte der nationalistische Abgeordnete Henry Franklin-Bouillon, frankreichfeindliche Passagen aus Mein Kampf rezitierend, kategorisch die Möglichkeit einer Verständigung mit Nazi-Deutschland: „C'est impossible, même si vous le vouliez." Er warnte eindringlich, Hitlers Versicherungen für bare Münze zu nehmen, und nannte den von Goy gewählten Weg geneigter Konzilianz eine „fürchterliche Gefahr" für die Sicherheit des Landes, geeignet, die Paktverhandlungen mit Sowjetrußland zu sabotieren. Deutschlands Veteranen stünden unter strenger Kuratel ihrer Regierung und Heß' Königsberger Rede sei nichts als ein Köder, dem Goy prompt erlegen sei. Ihm und besonders Robert Monnier, dem er Unregelmäßigkeiten in Bankund Privatgeschäften unterstellte, sprach Franklin-Bouillon die Qualifikation ab, im Namen Frankreichs mit einer Macht zu verhandeln, zu deren Herrschaftsaxiomen nach wie vor die Vernichtung des westlichen Nachbarn zähle99.

In dieser prekären Situation zeigte sich, daß Otto Abetz schwerlich einen wirksameren Hebel als die Frontkämpfer hätte finden können, um die Franzosen für Hitlers Avancen empfänglich zu stimmen. Die vielgescholtenen Berlinfahrer trotzten der stürmischen öffentlichen Diskussion, warfen bereitwillig ihren moralischen Kredit in die Waagschale und verhalfen so ihrem Anliegen, Brücken über den Rhein zu schlagen und die Aussöhnungsbereitschaft des ,Dritten Reiches' möglichst unbefangen zu erkunden, binnen kurzem zu erstaunlicher Popularität. Robert Monnier betonte in einer tumultuösen Veranstaltung im überfüllten Club $\mathrm{du}$ Faubourg, in deren Verlauf wiederholt auf die nationalsozialistischen Terrormaßnahmen und Aufrüstungsbestrebungen hingewiesen wurde, den privaten Charakter der Reise. Man habe sich aus erster Hand über die deutsche Frankreichpolitik informieren wollen. Scharf wandte er sich gegen jede Panikmache, die den eigenen Interessen nur schade. Er persönlich glaube an Hitlers Friedenswillen. Heß habe ihm auf Französisch gesagt, daß Deutschland zur Aussöhnung be-

weniger auf Versöhnung angekommen als auf eine Stärkung faschistischer Strömungen in Frankreich, hielt zumindest Distelbarth für „unberechtigt“; Lebendiges Frankreich, S. 190.

99 Annales de la Chambre des députés, Nouvelle série, Débats parlementaires, $3^{\mathrm{e}}$ séance du 30 novembre 1934, S. 2836-2848. Zu den Anwürfen gegen Monnier, Verwaltungsrat der von Betrugsaffären geschüttelten Pariser Banque centrale du commerce, ferner Berichte der Sûreté Nationale vom 28. 11. und 10. 12. 1934; AN, F 7/13433. Abetz zufolge schürte Franklin-Bouillon auch den Verdacht, Goy habe von Hitler so viel Bestechungsgeld kassiert, daß man gezwungen sei, den Zahlungsverkehr künftig in „Goys“ statt in Francs abzuwickeln. Das offene Problem, S. 54; danach Duroselle, La décadence, S. 207. Das Parlamentsprotokoll vom 30. November erwähnt diesen Vorwurf nicht. Für Goy, der von einer starren Frontstellung zwischen revisionistischen und dem Status quo verpflichteten Staaten abriet, ergriff der Neosozialist Barthélémy Montagnon Partei. Er hielt Aussprachen mit dem ,Dritten Reich für unumgänglich unter Hinweis darauf, wie tief die NS-Bewegung in der deutschen Bevölkerung gründe. Prompt wurde Montagnon von der deutschen Presse als Kronzeuge dafür präsentiert, „wieweit die Wandlung der Geister “ in Richtung einer Verständigung bereits gediehen sei (Völkischer Beobachter, 22. 12. 1934). Mit demselben Tenor äußerten sich in den folgenden Tagen in VB-Interviews, die zweifellos die Debatte in Frankreich anheizen sollten, unter anderem Pierre Cot (23./24. Dezember), Drieu La Rochelle („Hitler flößt Vertrauen ein“, 25. Dezember) und Goy (6./7. 1. 1935). 
reit sei, weil es seine Ehre wiedergefunden habe. Dieses psychologische Moment erscheine von ausschlaggebender Bedeutung ${ }^{100}$. Jean Goy stellte es als vaterländische Pflicht dar, für die Verständigung zu arbeiten. Er war ebensowenig wie Monnier frei von gutgläubiger Naivität. Dem Abendblatt La Presse erzählte er, man habe in bequemen Sesseln Platz genommen und Hitler, der "eher als ehemaliger Soldat denn als Staatschef" sprach, gelauscht. Der ,Führer" vermittle den „Eindruck eines Menschen von gut ausbalanciertem Gleichgewicht", worin sich notwendigerweise ein "intellektuelles und moralisches Gleichgewicht" spiegele101. Anläßlich der UNC-Versammlung am 21. November in Vincennes unterstrich er die politische Verantwortung und Zuständigkeit der Frontkämpfer für die Geschicke Frankreichs. Ein Bericht der Sûreté zitiert ihn mit den Worten: „Il faut que nos diplomates et hommes politiques, dont l'incompétence n'est plus maintenant à démontrer, laissent la place aux anciens combattants pour traiter les destinées de la France et c'est pourquoi l'U.N.C., qui en a assez de toutes ces conférences oiseuses au bord des lacs suisses, italiens et autres, a décidé de passer aux actes." Heß' Rede am 8. Juli und Hitlers Äußerungen ergäben jenes formelle deutsche Engagement, „que j'avais toujours recherché"102. Den letzten Aspekt vertiefte Goy, unverkennbar autoritäre Neigungen verratend, in einem Interview für das Petit Journal am 30. November: Frühere Verhandlungen seien vergeblich gewesen, weil die Gesprächspartner "nicht wirklich die Herren Deutschlands waren". Nun aber habe man es mit einer Reichsregierung zu tun, die nicht Gefahr laufe, schon morgen durch den Verlust der parlamentarischen Mehrheit desavouiert zu werden ${ }^{103}$.

Goy durfte sich in seinem Engagement umgehend bestätigt fühlen. Am 26. November gelangte der UNC-Verwaltungsrat mehrheitlich zu der Auffassung, daß er den Franzosen durch seine Reise wichtige Informationen erschlossen habe. Der Vorstand wurde ermächtigt, nützlich erscheinende Kontakte mit autorisierten deutschen Vertretern weiterzuverfolgen ${ }^{104}$. Solchermaßen gestärkt, trat der Berlinfahrer im Parlament Franklin-Bouillon entgegen und warnte davor, einen „Stahlring" um Deutschland zu legen und das überkommene System militärischer Blockbildung zu perpetuieren. Frankreichs Frontkämpfer wollten sich nicht an die Stelle der Staatsmänner drängen, im Konfliktfall sich aber auch nicht den Vorwurf machen müssen, Verhandlungschancen verschenkt zu haben ${ }^{105}$. Die Vetera-

100 Bericht der Sûreté Nationale vom 30.11. 1934; AN, F 7/13433. Bericht eines „Vertrauensmannes in Paris“ an das Auswärtige Amt, o.D.; PA/A'A, R 70556. In einem auch in Deutschland zitierten Zeitungsbeitrag rechnete Monnier mit allen „berufsmäßigen Brunnenvergiftern" ab; DFM, Dezember 1934, S. 81.

101 Zit. nach DNB-Rohmaterial vom 19. 11. 1934, abends; PA/AA, R 70556.

102 Bericht vom 22. 11. 1934; AN, F 7/13433.

103 Le Petit Journal, 30. 11. 1934.

104 DNB-Rohmaterial vom 26. 11. 1934, abends; PA/AA, R 70556. Das Journal des Débats nannte die Beschlüsse „verwunderlich und beunruhigend“. Hitlers Taktik, unmittelbar auf die französische Öffentlichkeit einzuwirken und sie in zwei Lager zu spalten, zeitige erste Ergebnisse. Das sei aber nur möglich durch die Verblendung jener, die sich zu solchen Manövern herbeiließen.

105 DNB-Rohmaterial vom 1. 12. 1934, morgens; PA/AA, R 70556. Dem Völkischen Beobachter (6./7. 1. 1935) sagte Goy, Franklin-Bouillon handele falsch, Hitler ausschließlich 
nen als nützliche diplomatische Hilfstruppe - an diesem Image, das die scheinbar auf gleicher Wellenlänge funkenden deutschen Kameraden ebenfalls pflegten, feilte der künftige UNC-Boß. Am 11. Dezember sprach er vor 800 begeisterten Zuhörern in Marseille, auf Einladung der „Nouvelle école de la paix“, unter deren Auspizien auch Jules Romains für eine deutsch-französische Annäherung warb. Nach neuerlichem Rekurs auf die legendäre Heß-Rede, die nur als eindeutiges Bekenntnis zum Frieden gewertet werden könne, bezeichnete Goy den seitherigen erfreulichen Verlauf der Saarverhandlungen und die „sichtbar eingetretene Entspannung " in den gegenseitigen Beziehungen als unmittelbare Folgen seiner Aussprache mit Hitler. Damit sei Frankreich ein "ungeheurer Dienst" erwiesen worden. Die Frontkämpfer hätten an Stelle der Diplomaten gehandelt, überließen nun aber gern der Regierung den Ruhm ${ }^{106}$.

Letztere verfolgte die beschriebene Entwicklung mit Sorge. Ministerpräsident Flandin beschwerte sich - „sehr verstimmt" - bei Botschafter Köster über sich häufende "deutsche Kundgebungen durch den Mund oder die Feder von französischen Staatsangehörigen", die keineswegs als kompetent gelten könnten. Kontroversen über die Zweckmäßigkeit solcher Aktionen störten empfindlich die Arbeit seines Kabinetts und machten das deutsch-französische Problem zusehends zum Zankapfel der ohnehin reichlich mit Streitfragen gespickten Parteienpolitik. Bis die Saarfrage vom Tisch sei, müßten halboffizielle Fühlungnahmen „unbedingt" unterbleiben. Sie zu unterbinden, weil sie zum gegebenen Zeitpunkt nur Unruhe und Polemik entfachten, verlangte am selben Tag der Kammerausschuß für auswärtige Angelegenheiten von Außenminister Laval ${ }^{107}$. Ins gleiche Horn blies der einflußreiche Senator Henri Bérenger: „Dunkle Besprechungen mit nichtqualifizierten Persönlichkeiten" statt offener Aussprachen auf Regierungsebene seien das "unangebrachteste Mittel“, die Verständigung voranzutreiben ${ }^{108}$. In Berlin reflektierte Botschafter François-Poncet über die Möglichkeit, Hitler könnte in Wahrheit nur daran gelegen sein, Verwirrung zu stiften und die Franzosen in fruchtlose deutschlandpolitische Debatten zu verstricken ${ }^{109}$. Botschaftsrat Arnal warnte, seine Regierung könnte bei einem zu raschen Ausbau der Frontkämpferbeziehungen gezwungen sein, sich öffentlich von den Wortführern der Veteranen zu distanzieren. Die für Frankreich zuständige AA-Abteilung nahm die Kritik zum Anlaß, nachdrücklich darauf hinzuweisen, wie sensibel die Pariser Kammer gegen Versuche sei, ihre Bedeutung als entscheidende Instanz für den Gang der französischen Politik zu schmälern und sie durch außerparlamentarische Faktoren zu ersetzen. Das Auswärtige Amt empfahl deshalb ein behutsames und vor allem koordiniertes Vorgehen, was freilich durch Eigenmächtigkeiten wie

nach früheren Erklärungen zu beurteilen. „Was zählt, ist des Kanzlers heutige Einstellung, und niemand kann die Anstrengungen leugnen, die der Reichsführer macht, um sich Frankreich anzunähern. " Gespräche zu verweigern sei eine „negative Haltung“, mit der sich „Männer der Tat" nicht zufriedengeben könnten.

106 Deutsches Generalkonsulat Marseille an Auswärtiges Amt, 12.12. 1934; PA/AA, R 70556.

107 Köster an Auswärtiges Amt, 30. 11. 1934, ebenda.

108 Zit. nach DNB-Rohmaterial vom 26. 11. 1934, abends, ebenda.

109 Zit. bei Mühle, Frankreich und Hitler, S. $329 \mathrm{f}$. 
die Parisreisen Oberlindobers und die Art der Einladung Goys und Monniers nach Berlin, „unter offenkundig absichtlicher Nichtbeteiligung des AA “, vereitelt werde ${ }^{110}$. Ebendies erzürnte auch Botschafter Köster in Paris, der ein Vertrauensverhältnis zwischen deutschen und französischen Veteranen als „äußerst wertvolles Moment" erachtete, inoffizielle Fühlungnahmen und die Einschaltung von Mittelsmännern, die außerhalb der Frontkämpferverbände ständen - damit war fraglos Abetz gemeint -, indessen klar verurteilte. Dadurch werde nur der „Eindruck unruhiger, [...] sich widersprechender Geschäftigkeit" hervorgerufen und ein Anbiederungsbedürfnis suggeriert, das Mißtrauen errege und die Gefahr berge, „daß die deutsche Aktion in innerfranzösische Gegensätze hineingezogen wird und versandet" ${ }^{* 111}$.

Ribbentrop, dessen auf zwischenstaatliche Kontaktpflege spezialisiertes ,Büro stetig expandierte, fochten solche Lamentos nicht an ${ }^{112}$. Lakonisch bestätigte er dem Auswärtigen Amt, daß „parallel laufende Initiativen“ auf dem Frontkämpfersektor von Nachteil seien ${ }^{113}$, ließ aber zugleich keinen Zweifel daran, in wessen Kompetenzbereich die Angelegenheit seiner Meinung nach gehörte, und stieß energisch nach. Vom 30. November bis 3. Dezember, als die Franzosen noch immer die Glaubwürdigkeit der Hitlerschen Aussagen vom 2. November und die Legitimation der Anciens combattants, den Reichskanzler aufzusuchen, diskutierten, weilte er ohne Vorankündigung in Paris, begleitet von seiner Frau, Oberlindober und Abetz. Er konferierte mit Goy, Pichot, dem populären kriegsblinden Abgeordneten Georges Scapini und - angeblich auf Vermittlung von Brinon und Bunau-Varilla - mit Pierre Laval ${ }^{114}$. Über den Inhalt der 45 minütigen Audienz im Quai d'Orsay drang nichts nach außen. Englische Zeitungskorrespondenten vermuteten schlicht eine Fortsetzung jener breitangelegten Sondierungsgespräche, die Ribbentrop unlängst noch in London geführt hatte ${ }^{115}$. Vom Foreign Office

110 Aufzeichnung v. Rintelen für Ministerialdirektor Köpke, 3. 12. 1934; PA/AA, R 70556.

111 Köster an Auswärtiges Amt, 14. 11. 1934; ADAP, C III.2, Nr. 324. Daß er nicht gänzlich falsch lag, zeigten die Reaktionen auf den Matin-Bericht vom 18. November. ReichsauBenminister v. Neurath unterstrich die Einwände seines Botschafters in einem Schreiben an Heß vom 19. November, das in Abschrift auch den Kollegen im Propaganda-, Innen-, Erziehungs- und Wehrministerium sowie dem Staatssekretär in der Reichskanzlei zuging. Ein "Wettrennen" $z$ wischen den mit Auslandspropaganda befaßten Stellen schade nur, betonte Neurath und ersuchte die NSDAP-Reichsleitung, dafür zu sorgen, daß das AA vor jedweder Aktion konsultiert werde. PA/AA, R 70556; Akten der Partei-Kanzlei der NSDAP, I, 1, Regest Nr. 10546.

112 Bezeichnend François-Poncets Eindruck, Ribbentrop, den er vor „Verständigungsreisen zum falschen Zeitpunkt" warnte, habe "erkennen lassen, daß er alle Diplomaten [...] für ausgemachte Trottel halte“. Aufzeichnung des Staatssekretärs v. Bülow (AA), 10. 12. 1934; ADAP, C III.2, Nr. 388. Auch zu englischen Veteranen suchte Ribbentrop damals Verbindung. Sein Vorschlag, für 1935 Zusammenkünfte mit deutschen Kriegsteilnehmern zu verabreden, wurde von der British Legion begeistert aufgegriffen. Bloch, Ribbentrop, S. 65.

113 Köster an Auswärtiges Amt, 14. November.

114 Berichte der Sûreté Nationale vom 1. und 3. 12. 1934; AN, F 7/13433.

115 Vgl. The Times, 27. November, 3., 4. und 5. Dezember 1934. Ausführlich Bloch, Ribbentrop, S. $62 \mathrm{ff}$. 
war er sehr reserviert behandelt worden ${ }^{116}$, und auch Laval schien keineswegs erbaut über die Visite und verlangte eine Einstellung der Frontkämpfer-Diplomatie. Signale für eine Entspannung seien zwar willkommen, müßten aber unbedingt auf amtlichen Kanälen gesendet werden, um unerwünschten Rückwirkungen auf die französische Innenpolitik vorzubeugen ${ }^{117}$. Ribbentrop ignorierte das geflissentlich und kündigte zum gelinden Entsetzen des Außenministers an, nach Möglichkeit noch vor Weihnachten gemeinsam mit Rudolf $\mathrm{Heß}$ aufzukreuzen, ein Ansinnen, gegen das sich Laval und Botschafter François-Poncet jedoch erfolgreich verwahrten ${ }^{118}$. Nicht zu verhindern war, daß die deutschen Emissäre in Pariser Veteranenkreisen auf wachsende Resonanz stießen. Sie luden gezielt solche Funktionäre nach Berlin ein, die sich bislang zögerlich oder abwartend verhalten hatten. Jean Desbons, Präsident der "Fédération interalliée d'anciens combattants“ (FIDAC), in der ausschließlich Kriegsteilnehmer der Siegermächte vertreten waren, signalisierte daraufhin Gesprächsbereitschaft. Jean Claude von den nationalistisch ausgerichteten „Prisonniers de guerre“ erwirkte von seiner Organisation eine grundsätzliche Reiseerlaubnis, unter der Auflage, daß er in Deutschland Umsicht walten lasse und sich auf den Part des ,aufmerksamen Beobachters“ beschränke ${ }^{119}$. Die folgenreichste Zusage gab Henri Pichot, der sich nicht länger zierte, Hitler aufzusuchen - „il faut voir cet homme“ -, ungeachtet eines Zusammenstoßes mit Ribbentrop. Dieser erregte sich während eines Essens darüber, daß verständigungswillige Franzosen als Landesverräter behandelt würden. Wenn es tatsächlich so schlimm um die gegenseitigen Beziehungen stehe, könne alles beim alten bleiben und man werde sich in fünf Jahren wiedersehen. Betretenes Schweigen machte sich breit, als Pichot gereizt erwiderte: „Dans cinq ans? La guerre pour 39 ? “ 120

Bei seinem Wunsch, nun doch nach Berlin zu kommen, trieb Pichot auch eine gewisse Eitelkeit. Nicht sein Verband, dem man das viel eher zugetraut hätte, sondern die vermeintlich so reaktionäre UNC leistete plötzlich Schrittmacherdienste

116 Bezeichnend eine Notiz des britischen Außenministers Sir John Simon von Ende November: „Assured us of Germany's peaceful intentions. No indication that he had anything else to say. Germany represented in this country by a most competent Ambassador - I do not believe that it is in the interest of good Anglo-German relations to go behind his back and conduct two Foreign Offices at the same time." DBFP, 2, XII, Nr. 231.

117 Campbell (Paris) an Simon, 3. 12. 1934, nach einem mündlichen Bericht Lavals; ebenda, Nr. 244.

118 Ebenda. François-Poncet an Laval, 3. 12. 1934; DDF, 1, VIII, Nr. 189. Köster an Auswärtiges Amt, 3. Dezember; PA/AA, R 70556. Akten der Partei-Kanzlei, Regest Nr. 10565: "Eine Reise des Reichsministers Heß nach Paris ,im Laufe Dezember" 1934 beabsichtigt." Am 7. Dezember gab der britische Botschafter Phipps Entwarnung: „French Ambassador has succeeded in getting Herr Hess' visit to Paris postponed“; DBFP, 2, XII, Nr. 282. Drei Tage später hakte Poncet, unter Hinweis auf Zeitungsberichte über eine unmittelbar bevorstehende Reise, nochmals im Auswärtigen Amt nach. Er insistierte, Heß' Anwesenheit in Paris sei derzeit "nicht genehm“. Staatssekretär v. Bülow versicherte, daß ein solcher Besuch vorerst nicht stattfinden werde; Aufzeichnung Bülows, wie Anm. 112. Vgl. auch Mühle, Frankreich und Hitler, S. 330 f.; Bloch, Ribbentrop, S. 66; Kordt, Nicht aus den Akten, S. $88 \mathrm{ff}$.

119 Berichte der Sûreté Nationale vom 10. und 11. 12. 1934; AN, F 7/13433.

120 Pichot, Et ce fut quand même la guerre, pag. 22. 
im deutsch-französischen Dialog. „Le voyage à Berlin de nos camarades Jean Goy et Robert Monnier n'a été possible que parce que d'autres avaient su faire le premier geste", stellte er klar und verwies auf seine diskreten Kontakte zu Oberlindober und Abetz seit August, die nun Früchte trügen ${ }^{121}$. Der Wirbel um die Kollegen mahnte jedoch zur Vorsicht. Ehe Pichot am 19. Dezember zusammen mit UF-Generalsekretär Maurice Randoux aufbrach, sprach er bei Laval vor, um zu demonstrieren, daß die Union fédérale loyal zur Regierung stand, im Einvernehmen mit ihr handelte und nicht für ein falsches Spiel zu mißbrauchen sei ${ }^{122}$. Auch öffentlich versuchte er den Boden zu bereiten: In Beiträgen für L'Euvre und die Cabiers de l'Union fédérale warnte er davor, autoritär regierte Länder gleichsam unter Quarantäne zu stellen; Europa bestehe nun einmal nicht aus lauter Demokratien. Die Anciens combattants huldigten beileibe nicht dem Hitlerismus, es gehe ihnen schlicht darum, einen friedenssichernden Modus vivendi zu finden. Auf diesem Gebiet hätten sie eine „moralische Mission“ zu erfüllen: „Notre rôle est d'aérer l'atmosphère franco-allemande, de rechercher et d'exploiter les bonnes volontés, de préparer les esprits à des gestes compréhensifs." Hierbei, so Pichot, wolle man sich weder politisch ausnutzen lassen noch den Regierenden und Parlamentariern ins Gehege kommen ${ }^{123}$. Einer, der ihm fest die Daumen drückte, war Henri de Jouvenel. "Je ne vois pas pourquoi la méthode qui a été bonne à Rome serait mauvaise à Berlin", meinte der mit der UF sympathisierende Senator zuversichtlich und erinnerte an die atmosphärisch wichtige Mittlerrolle der Weltkriegsteilnehmer bei den laufenden diplomatischen Verhandlungen zwischen Frankreich und Italien ${ }^{124}$.

Am 20. Dezember versammelten sich in der Reichskanzlei gemeinsam mit den französischen Gästen Ribbentrop, Heß, Oberlindober und Abetz. Erneut hinterließ Hitler gewaltigen Eindruck. „So freimütig [...], wie Frontkämpfer untereinander zu sprechen gewohnt sind“, verurteilte er den Krieg und gab inbrünstig der Hoffnung Ausdruck, die beiden "großen Kultur- und Soldatennationen“ möch-

121 Pichot, Offener Brief an Jean Luchaire, 30.11. 1934. Notre Temps hatte die UF am 28. November aufgefordert, es der UNC gleichzutun. Die eigenen Bemühungen herausstellend, entgegnete Pichot, man habe es nicht nötig, andere zu imitieren. Beide Dokumente abgedruckt in Cahiers de l'Union fédérale, Nr. 68, 1. 12. 1934. Goys Vorpreschen und latente Rivalitäten zwischen UF und UNC beleuchtet auch ein Bericht der Sûreté Nationale vom 3. 12.1934, "Les anciens combattants et les conversations franco-allemandes“; AN, F 7/14715.

122 Pichot, Et ce fut quand même la guerre, pag. 23.

123 Pichot, Le pont sur le Rhin, in: L'CEuvre, 13. 12. 1934. Ders., Français, Allemands et les Autres, in: Cahiers de l'Union fédérale, Nr. 69, 15. 12. 1934.

124 Jouvenel an Pichot, 13. 12. 1934, mit Bezug auf den L'CEuvre-Artikel; AN, 43 AS 1, dr. 2. Am 7. 1. 1935 unterzeichneten Laval und Mussolini ein Abkommen, das die französischitalienischen Differenzen bereinigen sollte und dem,Duce' wirtschaftlich freie Hand in Abessinien gewährte. Jouvenel, Sondergesandter in Rom, schrieb den französischen Veteranen großen Einfluß hinter den Kulissen beim Zustandekommen der Vereinbarung zu, desgleichen Distelbarth: Sie hätten „immer einen sanften Druck“ ausgeübt, „damit die Diplomaten sich endlich entschlössen, die eingefahrenen Geleise zu verlassen und zu handeln"; Lebendiges Frankreich, S. 206. 
ten endlich zusammenfinden ${ }^{125}$. Sattsam bekannten Beteuerungen, daß ElsaßLothringen zu Frankreich gehöre, erfolgreiche Abrüstungsverhandlungen möglich seien und die Rüstungsetats sinnvoller im sozialen Bereich eingesetzt würden, folgte eine aktuelle außenpolitische Erklärung, die Pichot nach Frankreich übermitteln sollte: Der ,Führer' versicherte nochmals feierlich, daß es bei der Saarabstimmung von deutscher Seite zu keinen Gewalttätigkeiten kommen werde, dafür wolle er persönlich Sorge tragen. Nach Erledigung der Saarfrage gebe es keine historischen Streitpunkte mehr zwischen Deutschland und Frankreich ${ }^{126}$. Wie sehr er seine Gäste in Bann zu ziehen und zu überzeugen vermochte, ist bei der Lektüre der zehn Jahre später verfaßten Erinnerungen Pichots immer noch greifbar. Mit den Vokablen „Eclatement! Volcanisme! Ouragan! Fulguration!“ charakterisiert er Hitlers tempermentvollen Auftritt. Dann: „Apaisement [...] Sourire [...] Regard éclairci [...] jaillissant comme une lave d'un cratère: ,Ich will den Frieden mit Frankreich." $" 127$

Das Echo dort fiel aus deutscher Sicht um einiges günstiger aus als noch vor Monatsfrist. Daß diesesmal „unanfechtbare Persönlichkeiten wie Pichot und Randoux" beim ,Führer" waren, habe selbst hartnäckige Kritiker in Verlegenheit gestürzt, meldete Botschafter Köster. Henri de Kerillis sei auf einer Frontkämpferversammlung vehement attackiert worden, seine Kameraden bei ihren Bemühungen um einen Ausgleich im Stich zu lassen und die Geisteshaltung eines Politikasters statt wahre Schützengrabengesinnung zur Schau zu tragen ${ }^{128}$. Der Pariser Korrespondent des Völkischen Beobachters verzeichnete eine „Auflockerung der französischen Öffentlichkeit zugunsten einer direkten Verständigung mit Deutschland“; ein „vor kurzem sozusagen noch verbotenes Thema“" war plötzlich, ganz im Sinne der Hitlerschen Strategie, „Tagesgespräch und Problem des Tages" 129 . Proteste und warnende Stimmen verstummten indes mitnichten. Mehrere Pariser Zeitungen wiesen beunruhigt darauf hin, daß die Anciens combattants eine "gefährliche Liebschaft" 130 mit ihren deutschen Partnern eingingen, tückisch vor allem deshalb, weil sie auf gänzlich ungleichen Voraussetzungen basiere. Pointiert, aus heutiger Perspektive bemerkenswert klarsichtig beschrieb Pierre Bernus im Journal des Débats die Divergenzen zwischen den dramatis personae: auf der einen Seite disziplinierte, weisungsgebundene Agenten des Hitler-Regimes, die ein sorgfältig berechnetes Manöver ausführten; auf der anderen eher unbedarfte Idealisten, die von den Methoden des,Dritten Reiches' ungenügende Vorstellungen hätten und Bauern auf dem Berliner Schachbrett seien. An der ihnen zugedachten Rolle hegte Bernus keinen Zweifel: Sie sollten die Mär von der national-

125 DNB-Meldung Nr. 2638 vom 20. 12. 1934, Erste Abend- und Nachtausgabe; PA/AA, $\mathrm{R} 70557$.

126 Vgl. Reisebericht von Maurice Randoux für die Cahiers de l'Union fédérale, in Auszügen abgedruckt DFM, Januar-Februar 1935, S. 133; Völkischer Beobachter, 22. 12. 1934; Abetz, Das offene Problem, S. 54.

127 Pichot, Et ce fut quand même la guerre, pag. $27 \mathrm{ff}$.

128 Köster an Auswärtiges Amt, 22. 12. 1934; PA/AA, R 70557.

129 Völkischer Beobachter, 6./7. 1. 1935.

130 L'Ere Nouvelle, 22. 12. 1934. 
sozialistischen Friedfertigkeit verbreiten, die Franzosen einschläfern und schließlich dazu bringen, Hitlers sinistre Pläne hinzunehmen ${ }^{131}$.

\section{Millionenheer des guten Willens: Frankreich und seine Veteranen}

Für die überwiegende Mehrheit der französischen Frontkämpfer kam diese Einsicht zu früh. Es entbehrt nicht der Tragik, daß ihre Begeisterungsfähigkeit und ihre tugendhafte staatsbürgerliche Pflichtauffassung, der Nation ein neuerliches Blutbad um jeden Preis ersparen zu müssen, der hinterhältigen NS-Propaganda von nun an auf Jahre hinaus einen effektvollen Resonanzboden boten. Henri Pichot und Jean Goy avancierten nach ihren Berlinreisen zu unumstrittenen Lenkern der mit Abstand größten Verbände und schufen gemeinsam mit anderen eine tragfähige Basis für das Verständigungswerk. Die Zeit leidenschaftlich geführter Kriege zwischen beiden Ländern sei passé, verkündete Pichot zum Jahreswechsel, um Kredit für Hitlers Beteuerungen werbend, und verlieh der nationalsozialistischen Bewegung im Überschwang der Gefühle das Prädikat „mouvement combattant [...] pour une bonne part" ${ }^{\prime 132}$. Mitte Januar 1935 nahm das UF-Präsidium „erfreut Kenntnis“ von den jüngsten Kontakten nach Deutschland und beauftragte den Vorstand, am Ball zu bleiben ${ }^{133}$. Auch bei der UNC sah man, zumal nach der ordnungsgemäß verlaufenen Saarabstimmung, die am 13. Januar ein eindeutiges Votum zugunsten des Reiches erbrachte, verheißungsvolle Perspektiven für eine dauerhafte Aussöhnung ${ }^{134}$. Fördern wollte man den Ausgleich auf eine Weise, die ebenso erfolgversprechend wie der eigenen Stellung und Funktion in der Gesellschaft angemessen erschien: durch unmittelbare Begegnung mit dem einstigen Feind, unabhängig und bar diplomatischer Sachzwänge, aber gerade deshalb zum Vorteil auch der Regierenden, denen eine breitangelegte, massenwirksame Verständigungsbewegung, von unten', ausgehend von der Versöhnung der Kriegsopfer, das Handwerk erleichtern sollte. Maurice Randoux hat Aufgabe und Spielraum wie folgt definiert: „Rien des devoirs, des soucis, des entraves, des responsabilités de la diplomatie officielle. Mais la volonté de l'aider, de lui ouvrir des chemins, d'éclaircir l'horizon. Une liberté de pensée et de langage qu'elle ne saurait se permettre, une liberté contrôlée, guidée par le bon sens, le sens des réalités, le sens critique dont les hommes de la guerre ne sont pas forcément dépourvus. “135

131 Pierre Bernus, Jeu dangereux, in: Journal des Débats, 22. 12. 1934. Weiteres Pressematerial zur Berlinreise Pichots in den Akten des Auswärtigen Amts; PA/AA, R 70557. Eine eingehende Erörterung der Berlinreisen von Goy und Pichot bei Mühle, Frankreich und Hitler, S. 326-333.

132 Pichot, Entre nous la guerre est finie, in: L'EEuvre, 30. 12. 1934.

133 Pichot, Et ce fut quand même la guerre, pag. 30.

$134 \mathrm{Vgl}$. Goy, Nach der Abstimmung: Furcht oder Hoffnung?, in: DFM, Januar-Februar 1935, S. 91-93.

135 Zit. im selben Heft, S. 133. 
Theoretisch glich dieser Ansatz der von Sohlbergkreis, RJF und Dienststelle Ribbentrop gepflegten Begegnungsphilosophie wie ein Ei dem anderen, was viel von der Leichtigkeit erklärt, mit der Abetz bei den Anciens combattants zum Ziel gelangte. Strahlkraft auf die französische Gesellschaft besaß er nicht zuletzt deshalb, weil die Wortführer der Veteranen glaubhaft versichern konnten, glühende Patrioten zu sein. Man nahm ihnen ab, daß sie stets nur das Beste fürs Vaterland wollten. Verhängnisvoll daran war, daß sie ihre Fähigkeit, einem Mißbrauch ihrer Ideale unverzüglich und entschlossen entgegenzutreten, überschätzten ${ }^{136}$. Die nationalsozialistische „offensive de charme " 137 wurde so präzise auf ihre Vorstellungen, wie fruchtbare zwischenstaatliche Gesellschaftsbeziehungen beschaffen sein müßten, zugeschnitten, daß eine Unterscheidung in Sein und Schein nicht einfach war. Hitler traf instinktsicher den Nerv der alten Kämpfer, schmeichelte ihrer Raison d'être, wenn er Pichot und Randoux erklärte, gerade das Engagement der Weltkriegssoldaten sei von besonderer Bedeutung für eine harmonische Gestaltung des deutsch-französischen Verhältnisses, weil ihnen in der Gesellschaft eine Beispiel- und Vorkämpferfunktion zukomme ${ }^{138}$. Das amtliche deutsche Kommuniqué hob in vollem Einklang mit dem Selbstverständnis der Berlinfahrer heraus, die Frontkämpfer wollten zum Segen der Völker für ein Rapprochement arbeiten, freilich ohne „den offiziellen Vertretungen beider Länder in ihren Aufgaben vorzugreifen" 139 . Weitere Bestätigung erfuhren Goy, Pichot und Kameraden aus dem Quai d'Orsay, wo man die Entwicklung inzwischen mit einigem Wohlwollen verfolgte. Der Berliner Botschaftsrat Arnal versicherte einem Gesprächspartner des Auswärtigen Amtes im Februar 1935, er halte "die Fortsetzung der wechselseitigen Beziehungen zwischen deutschen und französischen Frontkämpfern für sehr zweckdienlich“, da sie „auf alle Fälle ein Mittel seien, die Atmosphäre zu entgiften". Der Meinungsaustausch dürfe allerdings nur privaten, „nicht etwa Regierungs- oder auch nur offiziösen Charakter" besitzen ${ }^{140}$. Auch die französische Diplomatie stufte die Veteranen mithin als nützliches Hilfsinstrument ein, um unerwünschte politische Spannungen abzufedern, und begünstigte so Hitlers Taktik, beschwichtigende Worte unter Umgehung amtlicher Kanäle möglichst direkt unters Volk zu streuen.

Warum Frankreichs Frontkämpfer derart anfällig für die nationalsozialistische Propaganda waren und welch wichtige Multiplikatoren sie für Hitlers Friedensappelle darstellten, erhellt eine Untersuchung ihrer Mentalität und ihres demographisch-politischen Gewichts ${ }^{141} .1935$ lebten in Frankreich rund 5,5 Millionen Weltkriegsteilnehmer, das entsprach 42 Prozent der männlichen Bevölkerung

136 „Wenn Sie glauben, daß unsere tiefe Friedensliebe ein Zeichen von Schwäche und Selbstaufgabe ist und daß man sich uns gegenüber alles erlauben darf, befinden Sie sich im Irrtum“, mahnte Pichot seine deutschen Leser Anfang 1937. Ders., Je dis que la France est encore la France, in: DFM, Januar 1937, S. 4.

137 Ein Ausdruck von Alfred Kupferman, Diplomatie parallèle, S. 87.

138 Vgl. Reisebericht Randoux, wie Anm. 126.

139 Völkischer Beobachter, 22. 12. 1934; vgl. The Times vom selben Tag.

140 Aufzeichnung von Legationsrat Dumont über eine Unterredung mit Arnal, 22. 2. 1935; PA/AA, R 70557.

141 Die folgenden Zahlen nach Prost, Les anciens combattants, S. $131 \mathrm{ff}$. 
über 20 Jahre. Mehr als drei Millionen waren organisiert, und obwohl sie sich auf Dutzende von Verbänden verteilten, bildeten sie doch eine Massenbewegung, größer als die Gewerkschaften, mit erheblichem Einfluß auf öffentliche Meinung, Regierung und Parlament, den sie unter anderem in Forderungen nach wirtschaftlichen Reformen und sozialer Gerechtigkeit geltend machten ${ }^{142}$. Ihre Zusammensetzung, überwiegend aus Bauern und Kleinbürgern, glich einem „Querschnitt durch das ganze Volk“. Paul Distelbarth schwärmte von der „vollkommensten Volksorganisation, die man sich denken kann"; keinen Sonderinteressen verpflichtet, reflektiere der ,esprit combattant ${ }^{\prime}$ unverzerrt „die wahre öffentliche Meinung“, wirkten seine Ideen „wie Fermente, die die ganze Nation umzugestalten begonnen haben ${ }^{\alpha 143}$. In fast jedem Ort gab es Basisgruppen, die im Gemeindeleben eine wichtige Rolle spielten. Mehr als 1000 Verbandszeitschriften und Mitteilungsblätter trugen Neuigkeiten, natürlich auch die Kunde von den deutschen Verständigungsofferten, buchstäblich bis ins kleinste Dorf.

Aus der Tatsache, daß sie ihr Vaterland verteidigt und gerettet hatten, leiteten die hochangesehenen Veteranen ihren Anspruch ab, das, wahre Frankreich' zu verkörpern und befugt zu sein, im nationalen Interesse zu handeln ${ }^{144}$. Sie betrachteten sich in umfassendem Sinn als „bevorrechtigte Gläubiger" der Nation, für die sie Gesundheit und Leben riskiert hatten ${ }^{145}$. Neben ausreichender materieller Entschädigung und sozialrechtlichem Schutz verlangten sie vor allem eines: daß Vorsorge getroffen werde, um einen neuen Krieg zu verhindern. „Die Krönung unseres Werkes ist die Verteidigung des Friedens", postulierte Henri Pichot ${ }^{146}$. Das sollte einerseits durch Entschärfung innergesellschaftlicher Konflikte, die als wichtige Ursache für Gewaltbereitschaft nach außen galten, erreicht werden. Hierbei setzten die Anciens combattants auf sozialen Fortschritt, besonders auf eine gerechte Verteilung von Arbeit und Einkommen, Aspekte, denen sie sich vor allem nach den Februar-Unruhen 1934 intensiv widmeten ${ }^{147}$. Zum anderen er-

142 Beispielhaft der schon erwähnte „November-Plan“ 1934, den eine UF-Expertenkommission nach der Staatskrise vom Februar ausarbeitete. Die Programmschrift mit dem bezeichnenden Titel La République des Combattants wurde in 600000 Exemplaren verbreitet. Die Autoren forderten eine Stärkung der republikanischen Instanzen und einen Umbau der Wirtschaft mit dem Ziel, die Arbeitslosigkeit zu bekämpfen und jedermanns „Recht auf Arbeit“ zu verwirklichen. Die Ideale der Französischen Revolution wurden abgewandelt in "Liberté - Justice sociale - Paix “, wobei sozialer Friede als unverzichtbare Voraussetzung für die Vermeidung internationaler Konflikte galt. Vgl. Interview Pichots für Paris PTT-Radio, Mai 1937; AN, 43 AS 1, dr. 5. Distelbarth, Lebendiges Frankreich, S. $226 \mathrm{ff}$. Wenngleich sie letztlich apolitisch blieben, mußte mit den Anciens combattants "aufgrund ihrer quantitativen Stärke als innenpolitischem Faktor und groupe de pression" stets gerechnet werden“; Bellstedt, „A Aaisement“ oder Krieg, S. 197.

143 Distelbarth, Lebendiges Frankreich, S. 194, 196.

144 Robert Soucy, France: Veterans' Politics Between the Wars, in: Ward (Hrsg.), The War Generation, S. 85, gebraucht in diesem Zusammenhang den Ausdruck „the veterans' mystique“.

145 Pichot, „Pour le salut de la nation. Appel au parlement français“, 16. 3. 1938, abgedruckt in Cahiers de l'Union Fédérale, Nr. 141 vom 20. 3. 1938.

146 Ders., „Ansprache an die ehemaligen Kriegsteilnehmer von Hamburg“, 20. 11. 1936 (ins Deutsche übertragenes Manuskript); AN, 43 AS 2, dr. 1.

147 Auf dem UF-Kongreß des Départements Drôm 1934 schilderte Pichot Not und Arbeits- 
strebten sie, bar jeglicher Revanchegelüste und schwüler Schützengrabenmystik, internationale Verständigung, gerade mit den ehemaligen Gegnern, bei denen man dieselbe Besonnenheit, die gleichen Einsichten und Ziele voraussetzte. Die Männer auf der anderen Seite des Stacheldrahts mußten das Grauen genauso erlebt und als Warnung begriffen, genauso gelitten und genug davon haben. In gemeinsamer Anstrengung sollten die „Hüter der Erinnerung “148 deshalb Mißtrauen abbauen und Wegbereiter einer friedvolleren Zukunft sein. Sie seien „dazu berufen“, einen Beitrag zur Befriedung der Welt und vor allem zur Entspannung des deutschfranzösischen Verhältnisses zu leisten, erklärte Jean Goy am 16. Januar 1935 auf einer gutbesuchten Veranstaltung der "Union belge pour la Société des Nations“ in Brüssel. Deutsche Beobachter priesen die ausgezeichnete propagandistische Wirkung seines Vortrags. Besonderen Eindruck machte, daß "Goy nie einen Zweifel darüber ließ, daß er ein $100 \%$ iger französischer Patriot sei, daß er aber gerade deswegen sich verpflichtet fühle, den Standpunkt der Patrioten anderer Länder, wenn er vernünftig und von gutem Willen beseelt sei, anzuerkennen"149. Goys , bonne volonté verleitete ihn sogar dazu, Verständnis für die deutsche Aufrüstung zu bekunden, angesichts des französischen und vor allem des russischen Militärpotentials, das Berlin mehrfach in "eindrucksvollen Statistiken" dokumentiert habe. Es sei indessen nicht Sache der ehemaligen Frontkämpfer, „sich auf das Gebiet technischer Erörterungen zu begeben“. Sie müßten in erster Linie das gegenseitige Vertrauen fördern, „unablässig das schwache Gebäude des Friedens mit festen Baustoffen untermauern"150.

Der aus tiefempfundener Verantwortung für die Nachlebenden gespeiste Pazifismus der französischen Veteranen und ihre prononcierte Ächtung des Krieges ${ }^{151}$ fanden starken Widerhall in einer vom Weltkrieg traumatisierten Gesellschaft, die ihre Energien im innerpolitischen Kräftespiel zerschliß, aber wenig Kampfbereitschaft gegen äußere Gegner demonstrierte, selbst wenn dies - etwa in der Rheinlandkrise 1936 - im eklatanten Widerspruch zur französischen Sicherheitspolitik stand $^{152}$. Nach furchtbaren Blutopfern wollte man endlich in Ruhe leben,

losigkeit in Deutschland zu Beginn der dreißiger Jahre und warnte davor, ähnliche Verhältnisse in Frankreich zuzulassen. „Hitler a gagné la partie parce que les citoyens allemands ont eu à choisir entre ces deux alternatives: le bulletin de vote libre ou le morceau de pain. Ils ont choisi le morceau de pain. Voilà où conduit la misère engendrée par le chômage." Abgedruckt in der Verbandszeitschrift Le rescapé du combat (Valence), September 1934 .

148 Wie Anm. 133.

149 Graf Adelmann (Deutsche Gesandtschaft Brüssel) an Auswärtiges Amt, 19.1. 1935, Stempelvermerk: „Der Herr Reichskanzler hat Kenntnis“; PA/AA, R 70557.

150 Goy, Der neue Abschnitt der deutsch-französischen Beziehungen und der Standpunkt der Frontkämpfer, in: Europäische Revue, Januar 1935, S. $1 \mathrm{ff}$.

151 Distelbarth konstatierte einen „fast leidenschaftlichen Glauben an den Frieden, als eine religiöse Idee“, in Kombination mit einer wohltuenden „Abwesenheit von Gepränge, von tönenden Worten, überhaupt alles Lauten“. Wie Frankreich den Waffenstillstand feiert, in: Deutsche Zeitung Bohemia (Prag), 18. 11. 1937.

152 Vgl. Roland Höhne, Innere Desintegration und äußerer Machtzerfall. Die französische Politik in den Jahren 1933-1936, in: Rohe (Hrsg.), Die Westmächte und das Dritte Reich 1933-1939, S. 177. 
wünschte Sicherheit vor allem dem unruhigen östlichen Nachbarn gegenüber. Die kurzlebigen Regierungen der ,Dritten Republik' aber hatten ein verläßliches Sicherheitsgefühl bisher nicht erzeugen können, trotz Locarno, trotz des kostspieligen Baus der Maginot-Linie. Nicht zuletzt deshalb suchte man die unmittelbare Begegnung, von Mensch zu Mensch', zumal die als tapfere Gegner von einst geachteten deutschen Kameraden unter Hitler regelrecht um Freundschaft warben ${ }^{153}$. Genügend Einfluß im eigenen Land, um auf diesem Weg etwas zu erreichen, trauten sich die französischen Frontkämpfer ohne weiteres zu. „Dites-vous que le président de l'U.F., élu par 900000 votants, a plus de voix que n'importe quel député", verkündete Pichot selbstbewußt vor Kameraden in Aubusson ${ }^{154}$. Wieviel innenpolitisches Gewicht die NS-Propaganda den Veteranen jenseits des Rheins und ihrem ausgedehnten Kommunikationsnetz beimaß, klingt in den überlieferten Dokumenten immer wieder an. Ihr "sehr beachtlicher“ Einfluß werde sich „ohne Zweifel weiter verstärken“, meldete ein vertraulicher Bericht für das Auswärtige Amt vom Frühjahr 1935. Das Wort der führenden Köpfe besitze "für uns und für Frankreich ein ganz anderes Gewicht, als das der sicherlich auch recht achtungswerten, aber einflußlosen Intellektuellen, die wir gelegentlich in Deutschland begrüßen durften“. Eindeutige Empfehlung: „Diese Verbindungen müssen von uns mit allen Mitteln, aber auch mit größter Vorsicht gepflegt und ausgebaut werden"155. Die Europäische Revue berichtete über „das riesenhafteste Interessensyndikat [...], mit dem Parlament und Regierung in Frankreich zu tun haben; seine Wirkung ist um so gewaltiger, als es nationale Ideen wie Vaterlandsliebe, Landesverteidigung, Heroismus usw. ins Treffen führt" 156 .

\section{Besuchsprogramme und flammende Appelle: Höhepunkte der Frontkämpferverständigung}

Das Jahr 1935 begann für die Friedensfreunde und jene, die sich dafür ausgaben, verheißungsvoll. Das Saarplebiszit, bei dem eine erdrückende Mehrheit von über 90 Prozent der Wähler für den Anschluß ans Reich stimmte, verlief ohne größere Zwischenfälle und schien eine "neue Epoche deutsch-französischer Beziehungen“ einzuläuten ${ }^{157}$. Der mäßigende Einfluß der Frontkämpfer galt vielen Beobachtern als erwiesen, weitere Initiativen waren damit hinreichend legitimiert. Beiderseits des Rheins wurde fieberhaft am Ausbau der Kontakte gearbeitet. „Unsere Aktion

$153 \mathrm{Vgl}$. Rolf v. Humann-Hainhofen, Les devoirs de l'homme, in: DFM, Januar-Februar 1935, S. 95. Aufgabe der Frontkämpfer sei es, "de contribuer de toutes nos forces à un rapprochement entre deux peuples vaillants de grande histoire et civilisation, pour servir ainsi au noble but de l'apaisement de nos patries et du monde“.

154 Redemanuskript vom 30. 4. 1937, pag. 20; AN, 43 AS 1, dr. 5.

155 „Die französischen Frontkämpferverbände und ihre Bedeutung für die Verhandlungen mit Deutschland“, Paris o.D.; PA/AA, R 70557.

156 Pierre Frédérix, Die innenpolitische Lage in Frankreich, in: Europäische Revue, September 1934, S. 574 .

157 So das überschwengliche Urteil der DFM, Januar-Februar 1935, S. 123, wie auch Henri Pichots; vgl. ders., Um den Frieden am Rhein, in: Europäische Revue, Januar 1935, S. 3-8. 
läuft weiter", sagte Jean Goy in einem Presse-Interview ${ }^{158}$. Etwa zur gleichen Zeit regelte Ribbentrop verbindlich die Zuständigkeiten, wobei er zum Zwecke größtmöglicher Einflußnahme auf Pärchenbildung setzte. Die Pflege der Beziehungen zur UNC übertrug er Rolf v. Humann-Hainhofen vom Kyffhäuserbund; der spätere Stabsführer der ,Dienststelle verströmte tiefe Genugtuung darüber, daß den Veteranen und ihren Idealen im ,neuen' Deutschland, anders als zu Zeiten der Weimarer Republik, gebührende Beachtung geschenkt werde ${ }^{159}$. Hanns Oberlindober sollte die Verbindungen zu Pichot und zur Union fédérale „fortentwikkeln", während Berlin-Pionier Robert Monnier als potentieller Mittler aussortiert wurde. Franklin-Bouillons Attacken hätten seinen Leumund irreparabel geschädigt, beschied Abetz das Auswärtige Amt ${ }^{160}$. Wachsende Differenzen mit dem AA, das weiterhin Störungen der offiziellen Außenpolitik befürchtete, veranlaßten dann Heß und das Reichskriegsministerium im August 1935, Ribbentrop mit der einheitlichen Leitung der Weltkriegsveteranen zu beauftragen - ein neuer $\mathrm{Er}$ folg für den ehrgeizigen Karrieristen, der ohne Abetz' Vorarbeit so nicht möglich gewesen wäre. Zur Organisation und Koordination von Veranstaltungen im „Geiste der Versöhnung “ wurde in der ,Dienststelle“ ein spezielles Frontkämpferreferat eingerichtet, dessen Leitung erst Hermann Kügler, bald darauf Heinrich Georg Stahmer übernahm ${ }^{161}$.

Unteutschs Folgerung, Abetz sei das Betätigungsfeld des Frontkämpfertums Anfang 1935 entzogen worden ${ }^{162}$, erscheint unzutreffend. Als Frankreichreferent der ,Dienststelle' blieb er nachweislich auch weiterhin in die Verhandlungen der Veteranen eingeschaltet. In der ersten Märzwoche begleitete er eine NSKOV-Delegation - Oberlindober, v. Cossel, v. Humann-Hainhofen und v. Trautmannsdorff - zu neuen Sondierungen nach Paris. Auch diese Visite soll von Luchaire, ferner von Bertrand de Jouvenel und Monnier vorbereitet worden sein. Berichten der Sûreté zufolge verliefen die Gespräche mit führenden Köpfen der großen französischen Verbände diesmal unbefriedigend: Pläne einer publicityträchtigen $\mathrm{Pa}$ risreise von Rudolf $\mathrm{Heß}$ wurden höchst reserviert aufgenommen, Versuche, die französisch-sowjetischen Beziehungen zu diskreditieren, abgewiesen. Statt dessen hagelte es Kritik an der aggressiven Rüstungspolitik des Reiches ${ }^{163}$. Auf die Wiedereinführung der allgemeinen Wehrpflicht in Deutschland am 16. März reagierten UF und UNC besorgt. Eine UNC-Delegation, auf dem Sprung nach Berlin zu weiteren Sondierungsgesprächen, verschob ihr Unterfangen ${ }^{164}$. „En parlant perpétuellement de paix et en armant moralement et materiellement au-delà des limi-

158 DNB-Material vom 10.1. 1935; PA/AA, R 70557.

159 Vgl. v. Humann-Hainhofen, Les devoirs de l'homme. Le rapprochement après le plébiscite, in: DFM, Januar-Februar 1935, S. $94 \mathrm{f}$.

160 Aufzeichnung v. Rintelen vom 12. 2. 1935 über einen mündlichen Bericht Abetz'; PA/ AA, Botschaft Paris 1050/1.

161 Anordnung des Stellvertreters des Führers vom 27. 8. 1935, zit. bei Jacobsen, Außenpolitik, S. 290. Vgl. ebenda, S. 286f. Stahmer war zugleich ,Stabsleiter der deutschen Frontkämpferverbände‘.

162 Unteutsch, Sohlbergkreis, S. 116.

163 Berichte der Sûreté Nationale vom 9., 11. und 12. März 1935; AN, F 7/13433 und 14715.

164 Forster an Auswärtiges Amt, 22. 3. 1935; PA/AA, R 70557. 
tes permises non seulement par les traités mais même par le simple souci d'une sécurité que personne n'entend troubler, votre pays joue un jeu fort dangereux", entrüstete sich Georges Lebecq in einem Brief an NSKOV-Chef Oberlindober ${ }^{165}$. Seine Beschreibung des deutschen Doppelspiels traf ins Schwarze, den nachgerade missionarischen Verständigungseifer der Anciens combattants aber bremsten solche Einsichten nicht.

Wenige Tage später erschloß Otto Abetz der Reichsregierung die Sympathien eines weiteren populären Frontkämpferführers. Gemeinsam mit Robert Lange, einem Bekannten aus Sohlbergzeiten und Vertrauten Luchaires, begleitete er den kriegsblinden Pariser Abgeordneten Georges Scapini (Union des aveugles de guerre), der bei einer Podiumsdiskussion über die politische Zweckmäßigkeit unmittelbarer Aussprachen zwischen deutschen und französischen Veteranen den Kassandrarufen Kerillis' Paroli geboten hatte ${ }^{166}$, zu einer Audienz bei Hitler. Das Treffen fand in Bad Godesberg statt, wo Scapini eine Zeitlang am Protestantischen Pädagogium zur Schule gegangen war. Dolmetscher Abetz registrierte Tränen in den Augen des ,Führers', als man den Franzosen hereinbrachte, mochte freilich nicht entscheiden, ob der Kanzler Ergriffenheit vortäuschte oder die Erinnerung an eigene Kriegserlebnisse ihn tatsächlich für einen Moment überwältigte. „Ich, der ich selbst vorübergehend erblindet war und das Augenlicht nicht wieder zu finden glaubte, kann ermessen, welches Opfer Sie Ihrem Vaterland gebracht haben", sagte Hitler, ehe er, die Emotionen beiseite wischend, seine Thesen zur Rüstungsfrage vortrug 167 . Die ,Droge Hitler' wirkte wie so oft. Nach mehrstündiger Unterredung war Scapini endgültig für die Verständigung mit dem ,Dritten Reich' gewonnen, eine Haltung, an die er 1940 als Befürworter der Kollaboration anknüpfte.

Daß Scapinis Autorität ein Pfund war, mit dem die NS-Propaganda wuchern konnte, veranschaulicht folgende Beurteilung durch André Germain: Wenn ein tapferer Mann wie er, der im Felde sein Augenlicht verloren, für Freundschaft und Verständigung eintrete, müßten „selbst die wildesten Chauvinisten auf ihn hören“ und die „empfindlichsten Nationalisten alter Prägung “ verstummen ${ }^{168}$. Unmittelbaren publizistischen Flankenschutz bot Jean Luchaire, der der Reise nach Godesberg eine kalmierende Wirkung auf das durch Wehrpflicht und Stresafront neuerlich belastete deutsch-französische Verhältnis zuschrieb. Zwar dämmerte $i h m$, daß sich das Kräftefeld zwischen beiden Ländern zu Frankreichs Ungunsten zu verschieben begann, doch hielt er, in seiner Argumentation den Frontkämpfern eng verwandt, an der Überzeugung fest, daß die Bewahrung des Friedens oberste

165 Abgedruckt in La Voix du Combattant, 23. 3. 1935.

166 Kühn (Paris) an Auswärtiges Amt, 12. 2. 1935; PA/AA, R 70557. DFM, März 1935, S. $174 \mathrm{f}$.

167 Zit. bei Abetz, Das offene Problem, S. 56. Vgl. Unteutsch, Sohlbergkreis, S. 117; DFM, Mai-Juni 1935, S. 260. Zu Hitlers zeitweiliger Erblindung durch Giftgas im Oktober 1918 siehe Fest, Hitler, S. $113 \mathrm{f}$.

168 André Germain, Der Weg zur Verständigung, S. 39f. Germain, von den Berliner Machthabern darob hofiert, sah europäische Kultur und christliche Zivilisation vor allem durch sowjetischen Expansionismus und jüdisches Großkapital bedroht. Vgl. ders., Hitler ou Moscou. 
Priorität haben müsse: „La paix ne se fait pas seulement avec des amis, elle se fait surtout avec les ennemis possibles" ${ }^{169}$. Dieser Satz hätte von Henri Pichot stammen können, der sich beim UF-Nationalkongreß Ende April in Le Touquet nachdrücklich zu seinen Berlin-Kontakten bekannte, die es ungeachtet aller Panikmache mit Realitätssinn (!) und Offenheit fortzusetzen gelte. Die Versammelten erteilten ihm hierfür ein offizielles Mandat ${ }^{170}$.

Der Verständigungswille der alten Kämpen überdauerte auch jene Demütigungen und Brüskierungen, die Hitler Frankreich in den nächsten Jahren in regelmäBigen Abständen zumutete, fast unbeschadet. 1935 rollten Besuchsprogramme an, die rasch an Umfang gewannen, andere Verbände und Bevölkerungsgruppen zur Nachahmung animierten und - ganz im Sinn der nationalsozialistischen Propaganda - ein sich stetig normalisierendes Nachbarschaftsverhältnis vorspiegelten. Immer wieder setzten dabei die Frontkämpfer neue Maßstäbe. Den Anfang machten 45 Mitglieder der „Fédération nationale des blessés du poumon“, die Ende Juni 1935 auf Einladung von Robert Bosch eine Woche in Stuttgart weilten und hernach deutsche Kameraden mit in ihre Lyoneser Heimat nahmen. Reichskriegsopferführer Oberlindober hieß die Franzosen willkommen und betonte, in Deutschland denke „kein Mensch an einen neuen Krieg“. Die jüngsten Turbulenzen um die deutsche Aufrüstung bemäntelte er mit einem für französische Ohren eingängigen Argument: „Weil wir unser Vaterland so lieben wie ihr, [...] sind wir auch auf unsere Sicherheit so wie ihr bedacht." Es folgten Kranzniederlegungen, Empfänge, Ausflüge und ein Besuch im Bosch-Werk Feuerbach, wo die Gäste "von Tausenden deutscher Arbeiter umringt und begrüßt" wurden ${ }^{171}$. Die Wirkung entsprach den Erwartungen der Gastgeber. „Es ist nicht zuviel gesagt, wenn man behauptet, daß die Leute überglücklich aus Deutschland zurückkamen und der Anerkennung voll waren“, zog ein Mitarbeiter des Deutschen Konsulats Lyon Bilanz. Etwaige Vorbehalte der Besucher waren hinweggefegt, sie sahen das ,Dritte Reich' nun erst einmal durch die sprichwörtliche rosarote Brille und „versicherten wiederholt, daß ihre Organisation nicht nachlassen würde, in ihren Annäherungsversuchen immer weiterzugehen und daß sie [...] sich durch keine Kritik und keine Widerstände [...] beirren lassen würde“. Soviel Begeisterung steckte an: Auch die Provinzpresse, so der Bericht aus Lyon, habe „in ansprechender Weise“ Notiz genommen, was für künftige Begegnungen „alle Aussichten“ eröffne ${ }^{172}$.

Das nationalsozialistische Konzept, friedensdürstenden Besuchern nach dem Munde zu reden, Skeptiker mit ausgesuchter Gastfreundschaft zu betören und ihnen durch üppigen protokollarischen Aufwand das erhebende Gefühl zu vermitteln, etwas Besonderes zu sein, ging in der Folge vielfach auf, wobei sich spe-

169 Luchaire, La France se dégage des périls de l'est européen [...] tandis que l'entretien Hitler-Scapini prouve qu'on peut encore faire en Occident une paix solide, in: Notre Temps, 26. 4. 1935.

170 Forster an Auswärtiges Amt, 26. 4. 1935; PA/AA, R 70557. Le 15e Congrès National de l'Union Fédérale, in: DFM, Mai-Juni 1935, S. 253.

171 DFM, Juli-September 1935, S. 279; DNB-Material vom 24. 6. 1935; Heuss, Robert Bosch, S. $660 \mathrm{f}$.

172 Wilde (Lyon) an Auswärtiges Amt, 3. 7. 1935; PA/AA, R 70557. 
ziell Otto Abetz als ein Meister dieses Fachs bewährte. Ein anschauliches Beispiel liefert UF-Generalsekretär Georges Pineau, der restlos hingerissen über einen viertägigen Berlinaufenthalt berichtete. Erlesene Mahlzeiten mit hochrangigen Würdenträgern des Reiches, die Teilnahme an Neuraths Neujahrsempfang für das diplomatische Korps, schließlich ein Empfang bei Hitler, der vehement die Nutzlosigkeit von Kriegen geißelte, erstickten jeden Rest an kritischer Distanz. Der Frontkämpfer übernahm gleichsam die Bürgschaft für Deutschlands friedliche Absichten. „Le Chancelier n'a pas ce masque sévère et brutal sous lequel les photographies le représentent", schrieb Pineau in kindlich anmutender Naivität. „Ses yeux sont bons. Et, pour dire ce que je crois être la vérité, Hitler offre plutôt l'aspect d'un timide que d'un violent." Auf solchen Boden konnte die NS-Propaganda säen, ohne Anstoß zu erregen, etwa den von Pineau pflichtschuldig weiterverbreiteten Hinweis, wenn etwas die deutschen Freunde vergraulen würde, dann Frankreichs Zusammenarbeit mit dem Osten - ein gezielter Hieb gegen die dem Abschluß zustrebenden Paktverhandlungen zwischen Paris und Moskau ${ }^{173}$.

Binnen kurzem entwickelte sich ein regelrechter Frontkämpfertourismus. Sonderzüge mit Tausenden von Veteranen und ihren Angehörigen überquerten in beiden Richtungen den Rhein, man überbot einander an Herzlichkeit und Zuwendung. Friedensliebe und gegenseitige Wertschätzung wurden wie Schutzengel beschworen, auf ungezählten Banketten, bei Vorträgen und Gedenkfeiern, Ausflügen und gemeinsamer Grabpflege. Man verteufelte übereinstimmend den Krieg, bekräftigte die absolute Notwendigkeit, einen neuen Waffengang zu vermeiden, und bemühte nimmermüde die Hoffnung, daß Revanchegelüste und Mißtrauen der Regierenden irgendwann dem guten Willen und gesunden Menschenverstand der Völker weichen müßten ${ }^{174}$.

Die Bühne für flammende Appelle gaben wiederholt Massenaufmärsche. Herausragend ein Friedensschwur, den über 30000 Veteranen, Abgesandte aller am Weltkrieg beteiligten Nationen, in der Nacht zum 13. Juli 1936 während einer ergreifenden Gedenkfeier auf dem Schlachtfeld von Verdun leisteten. An diesem "größten Ereignis, das die Frontkämpferbewegung für die Völkerverständigung bis jetzt zu verzeichnen hatte "175, nahmen 500 Deutsche unter Führung von Hauptmann a.D. v. Brandis, der einst das hartumkämpfte Fort Douaumont erstürmte, und auch Otto Abetz teil. „Jamais plus noble geste n'aura été fait sur une terre plus auguste", schwärmte Henri Pichot, der die Idee dazu mit einigen Kameraden ausgeheckt hatte und zur Verwirklichung Geldmittel von der Pariser Regierung erhielt ${ }^{176}$. Am 4. Juli 1937 wurden 1000 französische Veteranen in Freiburg

173 Georges Pineau, Le Comité France-Allemagne à Berlin, in: Cahiers de l'Union fédérale, Nr. 92, 10. 2. 1936.

174 Fundgruben für einschlägige Äußerungen und Berichte über den regen Austausch der Jahre 1935 bis 1938 sind die DFM und die Verbandszeitschrift Cahiers de l'Union fédérale, von der sich eine vollständige Sammlung im Nachlaß Pichot befindet (AN, 43 AS 6 und 7).

175 Leitartikel Le Rassemblement de Verdun, unsig., in: DFM, Juli 1936, S. 233.

176 Pichot, Et ce fut quand même la guerre, pag. $48 \mathrm{f}$. Ders., Le silence de Verdun, in: Cahiers de l'Union fédérale, Nr. 105, 20.7. 1936. Eine nicht minder bewegte Schilderung bei Abetz, Das offene Problem, S. $58 \mathrm{f}$.: „Wer diese Stunde miterlebt hat, wird sie nie verges- 
begrüßt, am 1. August sprach Pichot bei einer Großkundgebung im Berliner Olympiastadion vor mehr als 100000 Menschen. Die Menge klatschte frenetisch Beifall, als er sich auf deutsch an seine „Kameraden" wandte ${ }^{177}$. Ende Oktober fuhren 1600 Veteranen aus Baden, Württemberg und der Pfalz nach Besançon, marschierten gemeinsam mit französischen Verbänden unter dem Jubel der Bevölkerung durch die Stadt, ehrten die Gefallenen und erneuerten den ,Eid von Douaumont ${ }^{\star}$. Dazu erklangen die Nationalhymnen beider Länder, Trikoloren mischten sich mit Hakenkreuzfahnen ${ }^{178}$.

Es gelang Abetz, das Wirken führender französischer Frontkämpfer eng mit den Aktivitäten der Dienststelle Ribbentrop zu verzahnen, was eine noch gezieltere propagandistische Einflußnahme erlaubte. Im Ende 1935 gegründeten Comité France-Allemagne, Pendant zur kurz zuvor wiederbelebten und mit Mitarbeitern der ,Dienststelle' durchsetzten DFG, fungierten Goy und Pichot als Generalsekretäre. Ihre Verbände traten der Gesellschaft korporativ bei und bildeten fortan eine wichtige soziologische Komponente. Präsident wurde Commandant René-Michel L'Hôpital, ein ehemaliger Adjutant Marschall Fochs, nach dessen Rücktritt wegen der Rheinlandkrise Georges Scapini179. Eine wiederholt ins Auge fallende Verflechtung der Jugend- und Veteranenarbeit war ebenfalls maßgeblich Abetz' Werk, eingedenk seines erklärten Ziels, diese beiden Bevölkerungsgruppen zu einem gewichtigen Faktor im deutsch-französischen Verhältnis zu koppeln. Auch diese Entwicklung wurde 1935 angebahnt. Am 26. Juli sprach Henri Pichot auf dem Heldenfriedhof von Saint-Quentin zu 60 Charlottenburger Jungvolkbuben, die sich auf großer Frankreichfahrt befanden. Er appellierte an sie, nach dem Vorbild der Frontkämpfer "offen, ehrlich und guten Willens" zu fruchtbarer Zusammenarbeit mit ihren französischen Altersgenossen zu finden, statt wie die Väter und Großväter vernichtend übereinander herzufallen ${ }^{180}$. Die dreiwöchige

sen können“. Vgl. Das Archiv, Juli 1936, S. 572f.; DFM, Juli 1936, S. 233 ff., 271, sowie das August-September-Heft, S. $280 \mathrm{ff}$. Die UNC versagte ihre Teilnahme aus Protest gegen die Remilitarisierung des Rheinlands; Prost, Anciens combattants, I, S. 181. Die deutsche Delegation beeindruckte mit einer im Programm nicht vorgesehenen Kranzniederlegung in Verdun.

177 DFM, Juli-August 1937, S. 270; Pichot, Cent vingt mille Anciens Combattants manifestent pour la Paix, in: Cahiers de l'Union fédérale, Nr. 128/129, August-September 1937. Pineau befand, Pichot sei der beliebteste Franzose in Deutschland; ebenda, Nr. 92, 10. 2. 1936.

178 DFM, Oktober-November 1937, S. 361 f.; Cahiers de l'Union fédérale, Nr. 132, 10. 11. 1937; vgl. Haumann, Eine inszenierte Friedensaktion.

179 Vgl. DFM, Februar 1936, S. 72, und Kap. IV der vorliegenden Arbeit. Besonders der Umstand, daß Pichot als Exponent der Linken gelte, mache ihn zu einem überaus wertvollen Medium für die Nationalsozialisten, urteilte ein anonymes, wahrscheinlich aus der deutschen Emigrantenszene stammendes, nach Einschätzung des Pariser militärischen $\mathrm{Ab}$ wehrdienstes aber weitgehend zuverlässiges Dossier „Les formes de la propagande allemande" vom September 1938; MAE, Papiers 1940, Fonds Daladier/1, B1. 101-118, hier Bl. $115 \mathrm{f}$. Abetz schilderte seinen Vorgesetzten das linke politische Spektrum in Frankreich als „auf lange Sicht hinaus ausschlaggebend“. Abetz an SS-Hauptamt, 20.7. 1937; BDC/Abetz.

180 La République, 27. 7. 1935; Kreuz-Zeitung (Berlin), 28. Juli. Auszüge aus Pichots Rede ferner in DFM, August-Oktober 1935, S. 275 f., und in einem Reisebericht von Hans- 
Fahrt, die nach Paris, durch Loiretal, Normandie und Bretagne führte, stellte auch insofern ein Novum dar, als eine „Kombination von martialischer Erinnerung an den Weltkrieg und friedensbewegter Konzilianz", gepaart mit einem als Regimewerbung inszenierten dynamisch-disziplinierten Auftreten vor Ort, den deutschfranzösischen Jugendbeziehungen unter Trägerschaft der HJ neuen Auftrieb geben sollte ${ }^{181}$. Um der verständigungspolitischen Zielsetzung gerecht $\mathrm{zu}$ werden, scheuten sich die Organisatoren nicht einmal, dem populären Pazifisten Marc Sangnier Reverenz zu erweisen, der vor kurzem noch deutschfeindlicher Hetze beschuldigt worden war, auf dessen Anwesen in Bierville die Jungvolkbuben nun aber ungeniert campierten. "Intensive Vorbereitung durch den Sohlbergkreis" und eingehende Betreuung durch die Union fédérale und das "Groupement universitaire français pour la Société des Nations “ ermöglichten eine Reihe von Kontakten zur französischen Jugendszene. Die Heimkehrer waren begeistert - „wie oft reichte man uns Wein, wenn wir um Wasser baten" - und gelobten, das sei nur der Anfang gewesen, denn die in der $\mathrm{HJ}$ geeinte deutsche Jugend wolle "mit der Jugend Frankreichs gern in guter Kameradschaft leben". Zuweilen mochte Abetz tatsächlich davon träumen, alte Ideale auch unter nationalsozialistischen Vorzeichen verwirklicht zu sehen. Er hatte für die Fahrt beim Auswärtigen Amt einen Zuschuß von 2500 RM erbeten, der ob des „kulturpolitischen Wertes“ des Projekts umgehend gewährt wurde 182 .

An der Schnittstelle Jugend/Frontkämpfer florierten besonders die Beziehungen zur Union fédérale. Im Sommer 1936 durften sich mehr als 100 Angehörige der UF-Jugendsektion, zwischen 15 und 30 Jahre alt, von HJ und DFG betreut drei Wochen lang ein Bild vom ,Dritten Reich' machen. Ausführlichen Berichten in ihrer Verbandszeitschrift ist zu entnehmen, was den jungen Franzosen am ,neuen' Deutschland positiv auffiel: Gastfreundschaft, Ordnung und Disziplin, Strebsamkeit im Beruf, Gemeinschaftssinn, Lebenskraft und ein unbeugsamer Glaube an die "deutsche Bestimmung". Befremdlich, ja beängstigend empfanden sie den manischen Hang ihrer Nachbarn zu Aktionismus und Uniformen, den politischen Konformismus und Zwang zu bedingungslosem Gehorsam, die Allgegenwart des Staates sowie das völlig übersteigerte Rassedenken ${ }^{183}$. Es war bezeichnend für Pichots scheuklappenträchtiges Harmoniestreben, daß er solch augenfällige Defizite und von raubtierhafter Unberechenbarkeit kündende Merkmale des NS-Staates seinen Landsleuten gegenüber immer wieder zu erklären, wenn nicht schönzureden versuchte. So geschehen anläßlich eines Vortrags beim Rotary-Club Orléans, wo er es schlicht unfair nannte, den Deutschen stets mit kleinmütigem Mißtrauen zu begegnen. Sie fänden nun einmal keinen Geschmack

Erich Heidsieck, Deutsches Jungvolk wandert durch Frankreich, ebenda, S. 265-272, ebenfalls veröffentlicht im Reichs-Jugend-Pressedienst.

$181 \mathrm{Vgl}$. Tiemann, Jugendbeziehungen, S. $343 \mathrm{ff}$.

182 Abetz an Auswärtiges Amt, 12.6. 1935, und Antwortschreiben vom 24. Juni; PA/AA, $\mathrm{R} 98893$.

183 Accueillis en toute cordialité - cent-vingt Jeunes de l'Union fédérale font en Allemagne un intéressant et profitable voyage ", in: Cahiers de l'Union fédérale, Nr. 107-108, 15. 9./10. 10. 1936. Siehe auch DFM, August-September 1936, S. $298 \mathrm{f}$. (Randnotizen eines französischen Teilnehmers) und $321 \mathrm{f}$. (eine Chronik aus deutscher Feder). 
an Politik und Parlamentarismus, sondern liebten, so seine beruhigend gedachte Botschaft, von ihrem Naturell her Gründlichkeit, Befehle und ein geregeltes Gruppenleben. Fünfzehn Jahre Not und innerer Kämpfe hätten sie dazu gebracht, ihr Heil im ,Führer' zu suchen. Ihre Fähigkeit, Entbehrungen zu ertragen und ihrer Regierung ohne nachzudenken durch dick und dünn zu folgen, könnte in der Tat gefährlich werden, wäre Hitler nicht ein erklärter Mann des Friedens, was alles andere relativiere ${ }^{184}$. Aber auch grundsätzlich mochte Pichot unterschiedliche politische Systeme als Hindernis für einen Ausgleich nicht akzeptieren. „Für uns Kriegsteilnehmer ist es keines", versicherte er deutschen Veteranen und DFGMitgliedern. „Jedes Volk ist frei, bei sich zuhause zu leben, wie es wünscht. Der Frieden wird nicht aus der Gleichheit der politischen Staatsformen kommen, sondern aus dem Willen der Völker, der seinen Ausdruck im Willen der Regierenden finden muß, den ersten Dienern ihrer Völker. Wichtiger als das politische Regime ist die Art, wie ein Volk lebt, wie es arbeitet, wie es unter den verschiedensten Lebensumständen sich verhält." ${ }^{185}$

\section{Zerstörte Illusionen oder: die schwierige Einsicht, mißbraucht zu werden}

Als Patentrezept für eine „détente morale" verordnete Pichot, in diesem Therapieansatz von vielen Gleichgesinnten bestärkt, einen möglichst zahlreichen und vielfältigen Austausch an der Basis, der allein wechselseitiges Verständnis fördern könne, „volkstümliche Reisen“ statt symbolischer Einladungen. Im Zeitalter der Massenbewegungen genügten individuelle, vereinzelte Bemühungen nicht mehr, sondern die Völker selber müßten zusammenkommen ${ }^{186}$. Zu diesem Zweck wurde ein "Service courant des informations et échanges internationaux" eingerichtet, der Einladungen publik machen und potentielle Austauschpartner vermitteln sollte ${ }^{187}$. Die Voraussetzungen für ein Aufgehen der NS-Strategie, den Verständigungstourismus als hoffnungsfroh stimmende Zeitenwende erscheinen zu lassen, ihn aber gleichzeitig als Vehikel für eine breite propagandistische Streuwirkung zu nutzen, waren blendend. Wärmstens begrüßten UF und UNC ein Angebot Schirachs, 1000 französische Frontkämpfersöhne im Frühjahr 1938 zur HJ in

184 „Allocution devant le Rotary-Club“, Orléans, 22. 2. 1937 (Manuskript); AN, 43 AS 1, dr. 5.

185 "Allocution devant la D.F.G. et les A.C.: N.S.K.O.V. et Kyffhäuserbund“, gehalten in Bremen und Lübeck, 25./26.11. 1937 (Manuskript und deutsche Übersetzung); AN, 43 AS 2, dr. 1.

186 Ansprache Pichots in Hamburg an die DFG der Hansestädte, 26.11. 1937 (deutsche Übersetzung von Otto Abetz), ebenda. Wie sehr verschiedene germanophile Zirkel in diesem Punkt übereinstimmten, dokumentiert ein Beitrag Drieu La Rochelles für das HJFührerorgan Wille und Macht, das dem deutsch-französischen Verhältnis am 15. 10.1937 eine komplette Ausgabe widmete. Alles sei eine Frage „des Sichkennens, des lebendigen Kennenlernens“, meinte der Schriftsteller. „Also Reisen, Reisen und immer wieder Reisen!"

187 Notiz im Nachlaß Pichot; AN, 43 AS 2, dr. 1. 
die Ferien zu schicken ${ }^{188}$. Kurz zuvor hatte er Fühlungnahmen zwischen Jugendlichen beider Länder als „eine der schönsten Verheißungen unserer Zeit“ bezeichnet und den Wunsch geäußert, die alte Gegnerschaft möge in gemeinsamen Lagerfeuern "für immer verbrennen"189. Auch diese Offerte zeitigte eine nicht zu unterschätzende Öffentlichkeitswirkung. Die Deutsche Botschaft Paris wurde mit Anfragen zu Einzelheiten der geplanten Massenfahrt förmlich überschwemmt ${ }^{190}$. Nach dem ,Anschluß' Österreichs im März 1938 nahmen die Anciens combattants indessen unverzüglich Abstand von dem Unterfangen ${ }^{191}$. Verbindliche internationale Verträge seien zu gravierend verletzt worden, als daß der Reise noch die ursprüngliche Bedeutung zukommen könne, beschieden die Veteranen Schirach in einem offenen Brief 192 .

Ernüchternd endete für Pichot und seine Kameraden auch ein anderes Experiment auf internationaler Bühne. Das Tauwetter in den deutsch-französischen Frontkämpferbeziehungen hatte die FIDAC im Juli 1935 bewogen, zum ersten Mal überhaupt eine deutsche Delegation zu einer Vollversammlung einzuladen. Die in Paris anberaumte Konferenz vereinte Vertreter aus elf exalliierten Staaten, von deutscher Seite das NSKOV-Dreigespann Oberlindober, v. Cossel und Dick sowie v. Humann-Hainhofen (Kyffhäuser) und v. Bary (Stahlhelm). In mehreren Resolutionen forderten die Teilnehmer eine wirksame Rüstungsbegrenzung, die strikte Einhaltung gültiger Verträge und die Bereitschaft, zwischenstaatliche Streitfragen einem internationalen Schiedsgericht zu unterwerfen. Sie verpflichteten sich, durch möglichst objektive Würdigung anderweitiger Interessen, Eindämmung tendenziöser Meinungsmache und Erziehung der Jugend zu Frieden und Gerechtigkeit eine dem Entspannungsprozeß dienliche Atmosphäre zu fördern ${ }^{193}$. Oberlindober zeigte sich angenehm überrascht über die herzliche Aufnahme. Binnen 48 Stunden, versicherte er Reportern, habe man auf diese Weise mehr erreicht als die Staatskanzleien in vielen Jahren ${ }^{194}$. Das Echo in Frankreich wurde noch verstärkt durch den zur selben Zeit stattfindenden Besuch von 50 deutschen Veteranen in Lyon, die Herriot in seiner Eigenschaft als Bürgermeister als "erste Schwalbe des Frühlings" willkommen hieß195. War es bloßer Zufall oder eine flankierende Maßnahme, daß just in jenen Tagen auch Otto Abetz wieder

188 DFM, Dezember 1937, S. 410; Cahiers de l'Union fédérale, Nr. 132, 10.11. 1937: „Un puissant mouvement se dessine dans la jeunesse allemande pour un contact et une, entente' avec la France. Nous en reparlerons."

189 Schirach, Gruß an Frankreich, in: Wille und Macht, 15. 10. 1937, S. 4 f.

190 Tiemann, Jugendbeziehungen, S. 351. Als Termin war der 10.-24. April 1938 vorgesehen. Die Reise sollte von Freiburg über Stuttgart, Heidelberg, Frankfurt, Mainz, Köln, das Ruhrgebiet, Hannover und Hamburg bis nach Berlin führen. DFM, Februar 1938, S. 87.

191 Le Ministre chargé de la coordination des services de la Présidence du Conseil an das Ministère des Affaires Etrangères, 29. 3. 1938; AN, F 60/174.

192 Abgedruckt in Cahiers de l'Union fédérale, Nr. 141, 20. 3. 1938.

193 DNB-Rohmaterial vom 2. 7. 1935, abends. Forster (Paris) an Auswärtiges Amt, 4. Juli; PA/AA, R 70557. DFM, August-Oktober 1935, S. 283.

194 La Presse, 4. 7. 1935.

195 Forster an Auswärtiges Amt, 4. Juli. Bissiger Kommentar in L'Ere Nouvelle vom 2. Juli: "Hoffentlich folgen weitere Schwalben, nicht der Flug von Sperbern." 
werbend durch Paris zog? Mit Empfehlungsschreiben Brinons gewappnet, sondierte er diesmal die Stimmung in Journalistenkreisen ${ }^{196}$.

Ein englischer Antrag, den Austausch mit Veteranenverbänden ehemaliger Feindstaaten zu vertiefen und ihnen durch eine Umbenennung der FIDAC in „Fédération Internationale" den Beitritt zu ermöglichen, fand auf dem nächsten Kongreß im September in Brüssel keine Mehrheit ${ }^{197}$. Doch 14 Monate später, im November 1936, die etablierten Institutionen FIDAC und CIAMAC waren „an einem toten Punkt ${ }^{\prime 198}$ angelangt, Rom und Berlin durch eine ,Achse verbunden, wurde auf italienische Initiative ein Komitee gebildet, das die Satzung für einen nach allen Seiten offenen Frontkämpferbund ausarbeiten sollte ${ }^{199}$. Im Februar 1937 hoben Delegierte aus 14 Nationen in Berlin das „Comité international permanent des anciens combattants" (CIP) aus der Taufe. Ungeachtet aller Gegensätzlichkeiten der politischen Systeme wollten sie Verständnis und Solidarität füreinander in ihren Heimatländern fördern. Ob des weltweiten Interesses trieb die NS-Führung wiederum hohen protokollarischen Aufwand, glanzvolle Empfänge bei Göring, Blomberg, Heß und bei Hitler auf dem Berghof inbegriffen. Heß, dessen Königsberger Rede vom Juli 1934 erneut als wegweisend herausgestellt wurde, rechtfertigte routiniert und ohne Widerspruch zu ernten die deutsche Aufrüstung: Ein großes und zugleich schwaches Reich sei eine Gefahr für die internationale Stabilitär, weil es eine Versuchung für potentielle Angreifer darstelle. Der ,Führer' gab sich in bewährter Manier als Kamerad unter seinesgleichen, posierte bereitwillig für Erinnerungsfotos und bekräftigte, ein von Veteranen regiertes Land könne kein Interesse am Krieg haben ${ }^{200}$. Auf kritische Einwände französischer Zeitungen, die ein billiges Propagandamanöver der ,Achsenmächte‘ witterten, reagierten Goy und Pichot mit heftiger Presseschelte. Sie unterstellten Teilen der Journaille krankhaftes Mißtrauen und mutwillige Sabotage des Verständigungsprozesses ${ }^{201}$. Einmal mehr hatte ihre Gutgläubigkeit die Oberhand behalten. Ein Jahr später sollten sie eines Besseren belehrt werden: Zunächst lehnte es der italienische CIP-Vorsitzende Delcroix ab, im Namen des Comités den Einmarsch der Wehrmacht in Österreich zu verurteilen. Dann verlangten die Deutschen auf der CIP-Tagung im Mai 1938 in London turnusgemäß die Präsident-

196 Bericht der Sûreté Nationale vom 2. 7. 1935, „Au sujet de Otto Abetz, envoyé spécial de Ribbentrop"; AN, F 7/13433.

197 Bräuer (Deutsche Gesandtschaft Brüssel) an Auswärtiges Amt, 7.9. 1935; PA/AA, R 70558.

198 Pichot, Et ce fut quand même la guerre, pag. 55.

199 Prost, Anciens combattants, I, S. 184.

200 Pichot, Et ce fut, pag. 55 ff.; DFM, Februar 1937, S. 77; Das Archiv, Februar 1937, S. $1646 \mathrm{ff}$.

201 Vgl. Pichot, Une nouvelle internationale combattante. La réunion de Berlin 14-19 Février, in: Cahiers de l'Union fédérale, Nr. 118, 10. 3. 1937. Goy wetterte im Februar 1938, soeben von einer Berlinreise zurück, gegen „les criminels ou imbéciles qui se plaisent à répandre [...] de fausses nouvelles“, und bezeichnete - ganz zuverlässiges Sprachrohr der NS-Propaganda - die Achse Berlin-Rom und den Antikominternpakt als logische, „defensive" Antwort Deutschlands auf das französisch-sowjetische Beistandsabkommen. Gringoire, 18. 2. 1938; L'Euvre, 22. Februar ( $\mathrm{Et}_{t}$ M. Jean Goy de plus belle donne raison à l'Allemagne"). 
schaft und beharrten in ultimativer Form auf ihrer Forderung, obwohl Pichot, Goy und Delegierte aus Belgien, Jugoslawien und der Tschechoslowakei sie dringend ersuchten, mit Rücksicht auf die heikle politische Großwetterlage vorläufig zu verzichten. Als der deutsche Kandidat, der Herzog v. Sachsen-Coburg-Gotha, in einer Kampfabstimmung gewählt wurde und prompt eine vorab formulierte, maschinenschriftliche Dankesrede zückte, argwöhnten die Franzosen ein abgekartetes Spiel unter Regie der, Achsenmächte' und traten aus dem Verbund aus ${ }^{202}$. Man könne und wolle sich nicht mit sentimentalen Fühlungnahmen begnügen, während Europa in Flammen aufzugehen drohe, machte Pichot seiner Enttäuschung Luft ${ }^{203}$.

Die lange währende „Blindheit“ der französischen Frontkämpfer gegenüber den deutschen Doppelspielen steht nach Meinung von Antoine Prost in engstem Zusammenhang mit ihren ehrenwerten Zielen. Derart groß war ihr Sehnen nach Ruhe und Sicherheit, daß sie sich trotz zahlreicher Alarmsignale geraume Zeit gegen die Einsicht sträubten, ihr guter Wille werde mißbraucht ${ }^{204}$. Gerade bei Pichot ist das Festhalten an illusionären Hoffnungen, das qualvolle, dem Innersten widerstrebende Ringen um die Erkenntnis, daß Hitlers Worte mitnichten seinen letzten Absichten entsprachen, greifbar. Beredt suchte er seine ob deutscher Dreistigkeiten beunruhigten Landsleute zu beschwichtigen, vermittelte das Bild eines beispiellos dynamischen, herkömmliche Grenzen sprengenden, aber im Grunde friedfertigen Nachbarn, selbst wenn im Unterbewußtsein massive Z weifel nagten. Die Frage, ob das Reich Krieg wolle, verneinte er im Oktober 1936 auf einer UFVersammlung in Riom unter Hinweis auf die Haltung der deutschen Bevölkerung und Hitlers Beteuerungen. Im selben Atemzug mußte er eingestehen, daß der Preis unerträglich hoch ausfallen könnte: „La paix allemande, c'est la France enfermée dans l'ouest de l'Europe et ne s'occupant pas du reste. "Das aber war dem aufrechten Patrioten erklärtermaßen zu wenig. „Votre frontière n'est pas sur le Rhin “, belehrte er seine Zuhörer, „elle est en Autriche, en Tchéchoslovaquie. C'est la raison du pacte franco-russe, c'est un pacte de défense“205. Anläßlich des großen Frontkämpfertreffens von Besançon bestritt Pichot, der trügerischen Vorstellung anzuhängen, daß sich deutsch-französische Probleme "einfach mit einem Austausch von heiteren Mienen und höflichen Liebenswürdigkeiten" regeln ließen, doch müsse man einander ein Höchstmaß an Verständnis und Sympathie zollen, um eingewurzeltes Mißtrauen zu tilgen ${ }^{206}$. Über einen Auftritt vor 7000 Hamburger Veteranen im November 1936 notierte er: „L'accueil [...] est plus que chaleu-

202 Prost, Anciens combattants, I, S. 185. Pichot, Et ce fut quand même la guerre, pag. $75 \mathrm{ff}$. Der Herzog, Präsident der Vereinigung der deutschen Frontkämpfer-Verbände, international aber ein unbeschriebenes Blatt, war nach Pichots Einschätzung eine Wahl Ribbentrops.

203 Pichot, Il y a un mois, à Londres, in: L'CEuvre, 20. 6. 1938.

204 Prost, Les anciens combattants, S. 147.

205 Zit. nach Journal des Combattants et Mutilés du Puy-de-Dôme, November 1936, S. 6.

206 Ansprache Pichots am 24.10. 1937 (Manuskript in deutscher Übersetzung); AN, 43 AS 2, dr. 1. 
reux. Il est incontestable qu'il existe une commune résonnance interne entre gens de la guerre." 207

Der fast unerschütterliche Glaube an eine Wesensverwandtschaft aller Kriegsteilnehmer trug entscheidend dazu bei, die überwiegende Mehrheit der französischen Frontkämpfer ungewollt zu "Handlangern der Nationalsozialisten“208 werden zu lassen. Tatsächlich meinte es das Gros der ehedem kaiserlichen Landser wohl ebenfalls ernst mit der Aussöhnung - viele Zeugnisse sprechen eine ehrliche Sprache. Ziel der „Grabenkämpfer, der schlammwatenden Helden der Granattrichter" könne stets nur der Frieden sein, schrieb mit lyrischem Einschlag eine hessische Veteranengruppe an Botschafter Köster ${ }^{209}$. Ein Traditionsclub ehemaliger Infanteristen aus Bochum ersuchte die Pariser Botschaft um Adressen vergleichbarer französischer Organisationen. Seither habe man die Hauptaufgabe darin gesehen, wehrhaften Geist und Schießkünste der Mitglieder hochzuhalten. Nun aber stelle die Friedenspolitik des ,Führers' neue Aufgaben, im besonderen die Pflege freundschaftlicher Beziehungen zu Veteranen ehemaliger Feindstaaten, um eine fruchtbare Zusammenarbeit der Völker Europas vorzubereiten ${ }^{210}$. "Noch recht lange haben diese unvergeßlichen Stunden in uns nachgeklungen“, versicherte ein Hermann Teufel aus Frankfurt-Eckenheim im Namen seiner Kameraden Henri Pichot und bat um Bilder und Zeitungsmaterial über „die Weihe-

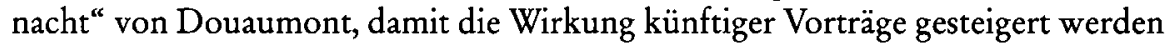
könne. Denn wo immer er Gelegenheit habe, so Teufel, „spreche ich von Eurem Wollen und Eurem Kampfe für das große Werk. Ich finde überall eine gläubige Hörergemeinschaft, die mithelfen will." Frontkämpfer wüßten eben, „was das Wörtlein Krieg bedeutet. Und sie alle sind sich einig in dem Wunsch, daß unseren Kindern dieses Leid erspart bleiben möge."211

Hinreichendes politisches Gewicht wuchs diesem Verlangen indessen nicht zu. Entgegen den Annahmen der Anciens combattants existierte ein Unterschied zwischen den politischen Systemen des ,Dritten Reiches' und der ,Dritten Republik“, der das Verständigungswerk zu zerstören imstande war: Während im demokratischen Frankreich der Druck der öffentlichen Meinung die Politik direkt beeinflußte und mitunter in andere Bahnen lenkte, gab im totalitären NS-Staat ein oberster Wille den Ausschlag. Ein Gegenbefehl konnte die Marschrichtung ändern, wie es geschah, als Hitler sich stark genug fühlte. Nur langsam verinnerlichten die französischen Veteranen die Lektion, daß ihre Kameraden am anderen Rheinufer nicht entfernt die gleiche Unabhängigkeit genossen, die Kontakte nicht auf paritätischer Grundlage fußten und Regierungen womöglich doch gegen den

207 Pichot, Et ce fut quand même la guerre, pag. 52.

208 Unteutsch, Sohlbergkreis, S. 111.

209 "Wir Kriegsfreiwillige von 1914/15" an Köster, 27. 6. 1934; PA/AA, R 70556.

210 Verband ehemaliger Jäger und Schützen von Rheinland und Westfalen an Köster, 31. 7. $1935 ;$ PA/AA, R 70558. In beiden Fällen bremste Köster den an ihn herangetragenen Verständigungseifer als verfrüht. "Wir wollen doch nicht vergessen, daß der Sieger und nicht der Unterlegene die Hand zur Versöhnung ausstrecken muß.“ Antwortschreiben vom 14. 8. 1935, ebenda. Die gegensätzliche Position der Botschaft zu Abetz wird auch an diesem Beispiel deutlich.

211 Brief an Pichot vom 30. 12. 1936, unterzeichnet von 24 Personen; AN, 43 AS 1, dr. 2. 
,Volkswillen` agieren konnten. Einschlägige Warnungen hatten sie, auf ihren ,Realitätssinn' vertrauend und dabei die roßtäuscherischen Qualitäten der NS-Propaganda fahrlässig unterschätzend, jahrelang in den Wind geschlagen ${ }^{212}$. Erst 1938 setzte sich die Einsicht durch, daß man düpiert, der leidenschaftliche Idealismus manipuliert worden war. Schlagartig brachen die Besuchsprogramme ab. Im Bemühen um friedliche Lösungen gehörten Goy und Pichot zwar zu den engagiertesten ,Munichois', doch spätestens im Frühjahr 1939 stimmten auch sie in den Chor jener ein, die energische, notfalls gewaltsame Gegenmaßnahmen gegen Hitlers Expansionismus befürworteten. Mit dem kollektiven Austritt ihrer Verbände entzogen sie dem Comité France-Allemagne die Massenbasis ${ }^{213}$.

Bis dahin leisteten die Veteranen der nationalsozialistischen Beschwichtigungspolitik unschätzbare Dienste. Es ist Otto Abetz' höchst fragwürdige Leistung, der NS-Propaganda diesen und andere Kanäle erschlossen zu haben, zugleich eine persönliche Tragödie und bezeichnend für sein Scheitern, daß er es schwerlich mit kriegerischen Hintergedanken tat. Sein ursprüngliches Wollen, so wie er es darstellte und überzeugend zu vermitteln wußte, deckte sich vielmehr so weitgehend mit der Verständigungsphilosophie der Anciens combattants, daß man geneigt ist, sein Wirken zumindest in diesem Punkt in milderem Licht zu beurteilen. Jules Romains nahm an oder wollte zumindest hoffen, daß Abetz unter Gewissensbissen litt ${ }^{214}$. Henri Pichot suchte derweilen Trost in der Weisheit, daß alles Handeln zwar letztlich an den Resultaten gemessen wird, begreiflich aber nur in Kenntnis der tieferen Absichten. Unter diesem Blickwinkel zählen seine ehrenwerten Motive und das politische Wagnis, das er ihretwegen einging 215.

212 Goy sprach von einer überaus bitteren Erfahrung. „C'est autrement que nous avions espéré cette collaboration [...] Nous nous sommes trompés. "Zit. nach Cahiers de l'Union fédérale, Nr. 164-165, 10.-25. 4. 1939, S. 20.

213 Siehe Kap. VII.

214 Romains, The Mystery of Ribbentrop \& Co.

215 Pichot, „Bilan 1916-1940“, pag. 1; AN, 43 AS 4, dr. 3. Deprimiert über den Zusammenbruch der ,Dritten Republik', für den er Systemschwächen, Dekadenzerscheinungen und mangelnden ,esprit combattant' verantwortlich machte, trat Pichot im Juli 1940 von seinen Ämtern zurück. Aus Furcht, wegen seiner Haltung nach dem Münchner Abkommen von den Deutschen verhaftet zu werden, wechselte er in die unbesetzte Zone. Auf eine Intervention bei Botschafter Abetz zugunsten seines kriegsgefangenen Sohnes Pierre verzichtete er: „Moi et les miens, nous ne devons rien à l'occupant. "Er half die pétaintreue, im Stile einer Einheitsorganisation gestaltete Légion français des combattants gründen, weil der Marschall in seinen Augen jene Frontkämpfertugenden verkörperte, die das Land so dringend benötigte. Hervorgetreten ist Pichot in der neuen Organisation jedoch nicht. Die Légion, nördlich der Demarkationslinie verboten, befehdete sich heftig mit der UF, die die Deutschen ebenso wie die UNC und zwei weitere Verbände zu propagandistischen Zwecken im besetzten Gebiet wieder zuließen, wofür sie politische Gefügigkeit erwarteten. AN, 43 AS 3 und 4; ferner AN, AJ 40/551, drs. 6 und 7 (Akten der Militärverwaltung zum Thema „Frontkämpfervereinigungen“); PA/AA, Nachl. Schleier/IV.2, Nr. 6: „Kriegsopfer- und Frontkämpferverbände“. - Etliche prominente Veteranen der dreißiger Jahre wählten nach der Niederlage 1940 den Weg in die Kollaboration. Scapini kümmerte sich in Berlin um die Interessen der französischen Kriegsgefangenen. Goy gehörte einige Zeit dem Direktorium von Marcel Déats Rassemblement national populaire (RNP) an. Randoux lenkte weiterhin maßgeblich die Geschicke der UF. 